\title{
LA-UR- $-98-1306$
}

\section{CONTENTS}

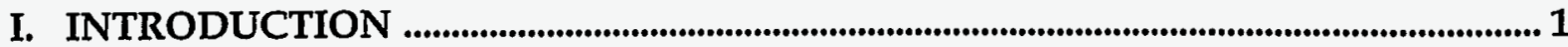

Fuel Cell Stack Research and Development............................................................................. 2

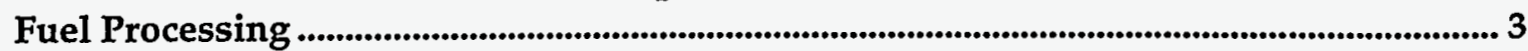

PEM Fuel Cell Modeling, Testing, and Evaluation .................................................................. 3

Direct Methanol PEM Fuel Cells ................................................................

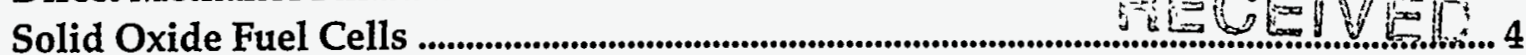

II. FUEL CELL STACK RESEARCH AND DEVELOPMENT ........................................ 5

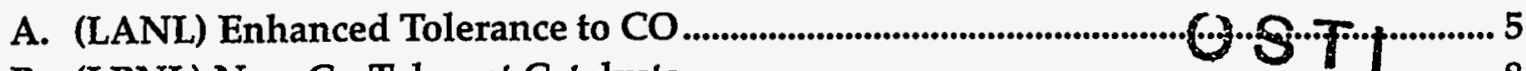

B. (LBNL) New Co-Tolerant Catalysts ................................................................................. 8

C. (BNL) X-ray Absorption Studies of Catalysts ........................................................................ 10

D. (LBNL) Fuel Cell Electrode Research: CO Bonding to Electrocatalysts ..................... 12

E. (LANL) Bipolar Plate Materials Development .................................................................. 14

F. (ORNL) Bipolar Plate Materials Development ...............................................................17

G. (LANL) Effective Cell \& Stack Humidification ............................................................ 17

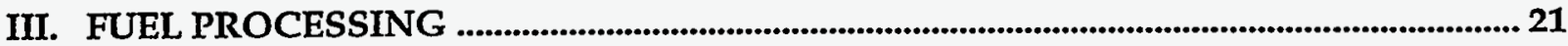

A. (ANL) Fuel Processor Development ................................................................................. 21

B. (LANL) Fuel Processing Research and Development - Preferential Oxidation .... 24

C. (ANL) CO Removal from Reformate .............................................................................................. 29

D. (PNNL) Microchannel Fuel Processor Components ......................................................... 32

IV. PEM FUEL CELL MODELING, TEST AND EVALUATION ........................................... 35

A. (ANL) Modeling of Automotive Fuel Cell Systems ........................................................ 35

B. (LANL) PEM Stack Modeling at Los Alamos National Laboratory ............................. 38

C. (LANL) PEM Stack Testing and Evaluation ....................................................................... 41

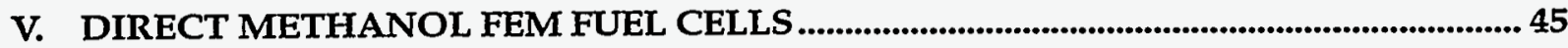

A. (LANL) Direct Methanol Fuel Cells ...................................................................................... 45

B. (NREL) Application of Combinatorial Synthetic Methods to the

Development of Electrocatalysts for

VI. Solid Oxide Fuel Cells .......................................................................................................................... 49

(ANL) Low Temperature Solid Oxide Fuel Cells...................................................................... 49

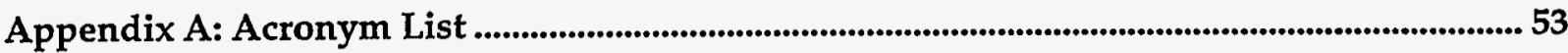

\section{MASTER FAT}




\section{DISCLAIMER}

This report was prepared as an account of work sponsored by an agency of the United States Government. Neither the United States Government nor any agency thereof, nor any of their employees, make any warranty, express or implied, or assumes any legal liability or responsibility for the accuracy, completeness, or usefulness of any information, apparatus, product, or process disclosed, or represents that its use would not infringe privately owned rights. Reference herein to any specific commercial product, process, or service by trade name, trademark, manufacturer, or otherwise does not necessarily constitute or imply its endorsement, recommendation, or favoring by the United States Government or any agency thereof. The views and opinions of authors expressed herein do not necessarily state or reflect those of the United States Government or any agency thereof. 


\section{DISCLAIMER}

Portions of this document may be illegible in electronic image products. Images are produced from the best available original document. 


\section{INTRODUCTION}

The Department of Energy (DOE) Fuel Cells for Transportation Program is structured to effectively implement the research and development $(R \& D)$ required for highly efficient, low or zero emission fuel cell power systems to be a viable replacement for the internal combustion engine in automobiles. The Program is part of the Partnership for a New Generation of Vehicles (PNGV), a governmentindustry initiative aimed at development of an 80 mile-per-gallon vehicle. Through the Fuel Cell Alliance (Figure 1), DOE National Laboratories play a major role in this program by performing highly focused R\&D addressing the critical technical barriers for fuel cell systems. The laboratories retain the intellectual property rights, but the results of their $R \& D$ activities are made available to their customers - the fuel cell suppliers. The laboratories also help suppliers overcome technical hurdles and provide independent test facilities to verify hardware performance for suppliers and automakers.

The Fuel Cells for Transportation Program is pursuing a fuel-flexible fuel strategy which utilizes the existing conventional fuel infrastructure as well as the alternative fuel infrastructures currently being developed. Use of conventional fuels encourages the initial market introduction and consumer acceptance of fuel cell vehicles by allowing refueling to be virtually identical to that of a conventional vehicle. Use of alternative and renewable fuels leads to greater energy security. The potential use of methanol, ethanol, or hydrogen from renewable energy sources affords an opportunity for a gradual transition to sustainable alternative fuels as the supply and distribution infrastructures are made available.

Therefore, DOE is developing a fuel-flexible fuel processor which will enable gasoline, methanol, ethanol, and natural gas to be utilized in fuel cell vehicles. As a result, a critical technical challenge for transportation fuel cell technology is the intolerance of the catalyst to carbon monoxide (CO) present at low levels in the reformate fuel stream. This is a major area of emphasis of the laboratory R\&D which includes two approaches to overcoming the CO barrier: (1) improving the tolerance of the fuel cell stack to $\mathrm{CO}$, and (2) decreasing the amount of $\mathrm{CO}$ from the fuel processing system. The laboratories have made significant progress toward solving the $\mathrm{CO}$ problem and advancing the state-of-the-art in fuel cell

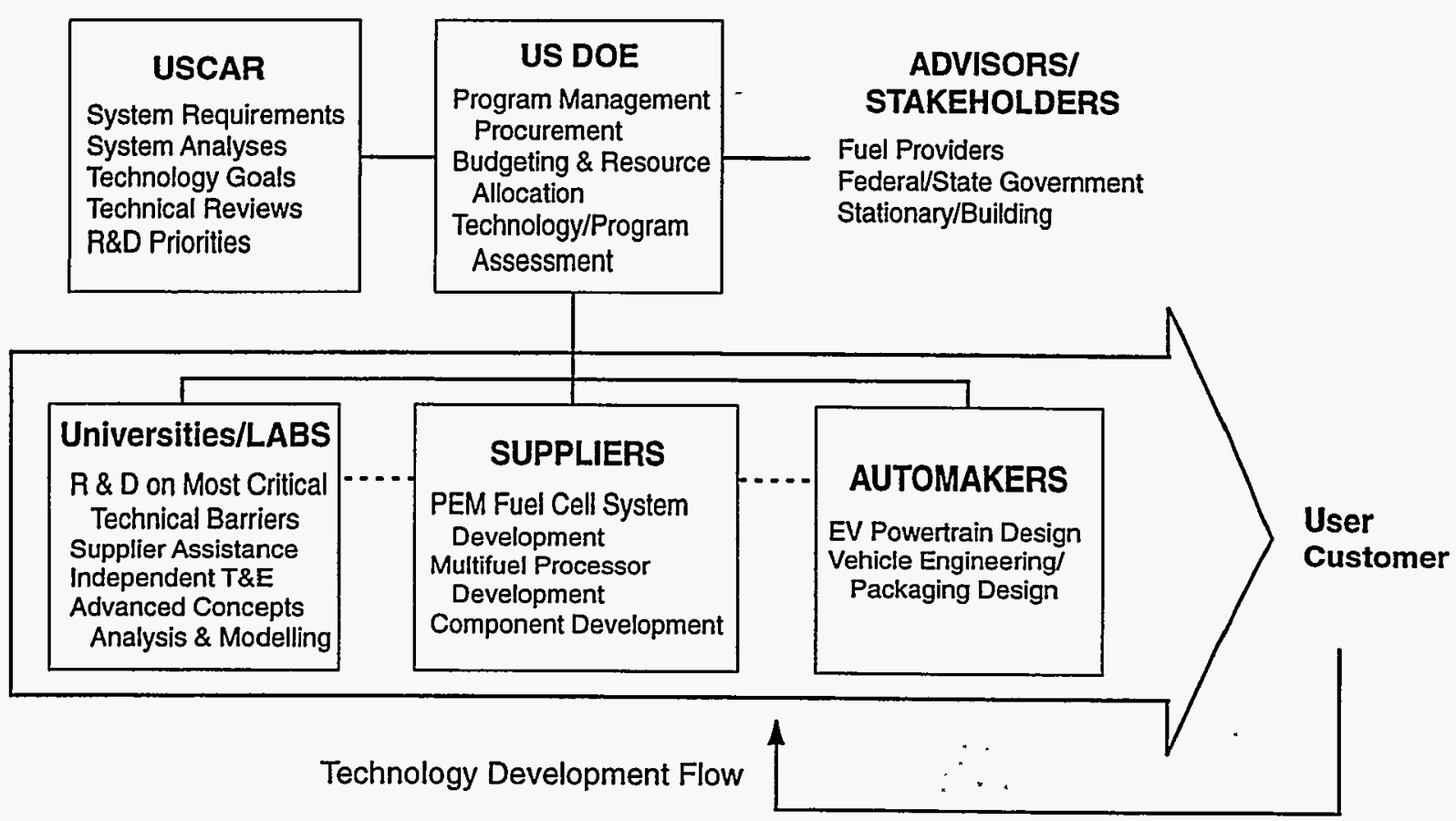

Figure 1. Fuel Cell Alliance 
. "Fuel Cells for Transportation FY97

- technology. Current R\&D activities are focused on proton-exchange membrane (PEM) fuel cell stack research and development; fuel processing; fuel cell modeling, test, and evaluation; and direct-methanol fuel cells.

This Annual Report summarizes the technical accomplishments of the laboratories during.1997. Participants include: Argonne National Laboratory (ANL), Brookhaven National Laboratory (BNL), Lawrence Berkeley National Laboratory (LBNL), Los Alamos National Laboratory (LANL), Oak Ridge National Laboratory (ORNL), Pacific Northwest National Laboratory (PNNL), and the National Renewable Energy Laboratory (NREL). During 1997, the laboratory R\&D included one project on solid oxide fuel cells; this project has since been terminated to focus Department resources on PEM fuel cells.

The technical component of this report is divided into five key areas:

- Fuel Cell Stack Research and Development

- Fuel Processing

- Fuel Cell Modeling, Testing, and Evaluation

- Direct Methanol PEM Fuel Cells

- Solid Oxide Fuel Cells

This work was presented at the Annual National Laboratory Fuel Cell R\&D Meeting in Washington, DC in July 1997. The proceedings of the Annual Meeting and the Summary Evaluation are available upon request from the Office of Advanced Automotive Technologies.

\section{Fuel Cell Stack Research and Development $B N L, L B N L, L A N L, O R N L$}

Fuel cell stack R\&D includes: (1) improving tolerance to carbon monoxide (CO) in fuel cell stacks, (2) developing effective cell and stack humidification strategies, and (3) developing improved catalysts, electrodes, and bipolar plates. Excessive $\mathrm{CO}$ in the fuel cell feed stream acts as a "poison" to the catalyst used in PEM fuel cells and degrades performance. Accomplishments in this area include

- Demonstrating CO tolerance in current systems at $1000 \mathrm{ppm}$ in short term operation and $100 \mathrm{ppm}$ in longer term operation.

- Devising in situ methods to monitor the interaction of $\mathrm{CO}$ with $\mathrm{Pt}$ and Pt-alloy catalysts.

- Identifying promising new catalyst materials through continuing research on the kinetics and mechanism of the electrode reactions in low temperature fuel cells.

- Demonstrating fuel cell system operation at $400 \mathrm{~W}$ with less than $3 \%$ parasitic power loss.

- Developing a nuclear magnetic resonance (NMR) method to study surface species on conductive electrodes.

- Demonstrating either high electronic conductivity or low permeability using bipolar plates fabricated from low-cost, non-conductive fibers and thermoset resins.

- Preparing slurry molded preforms for bipolar plates having minimum porosity using a phenolic resin treatment. 


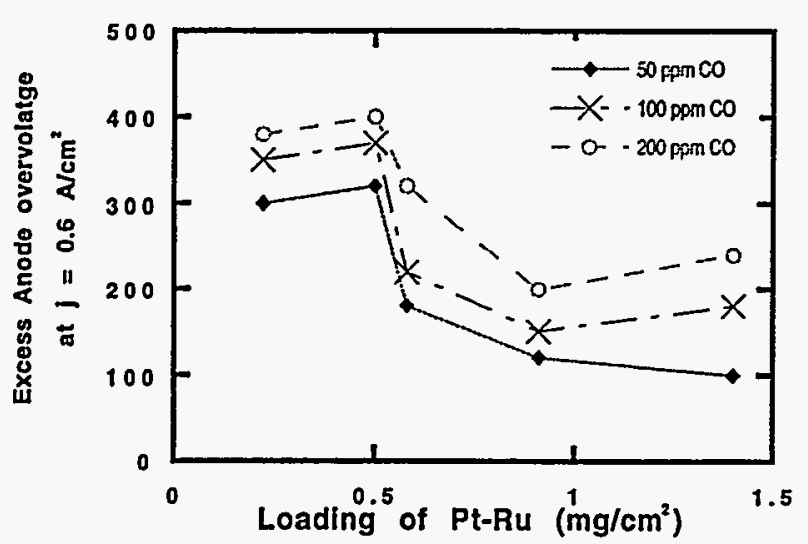

Figure 1. Dependence on Pt-Ru loading of anode loss at $0.6 \mathrm{~A} / \mathrm{cm}^{2}$ in the presence of various levels of $\mathrm{CO}$; cell operating at $80^{\circ} \mathrm{C}$.

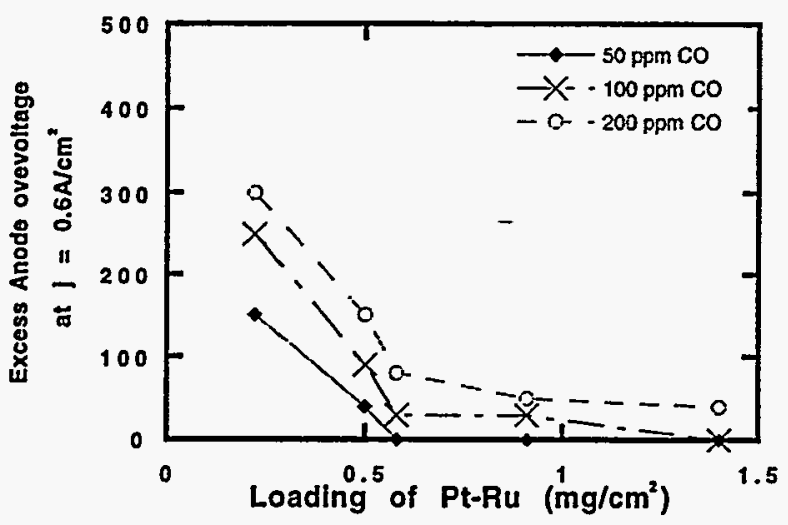

Figure 2. Dependence on $\mathrm{Pt}-\mathrm{Ru}$ loading of anode loss at $0.6 \mathrm{~A} / \mathrm{cm}^{2}$ in the presence of various levels of $\mathrm{CO}$; cell operating at $100^{\circ} \mathrm{C}$.

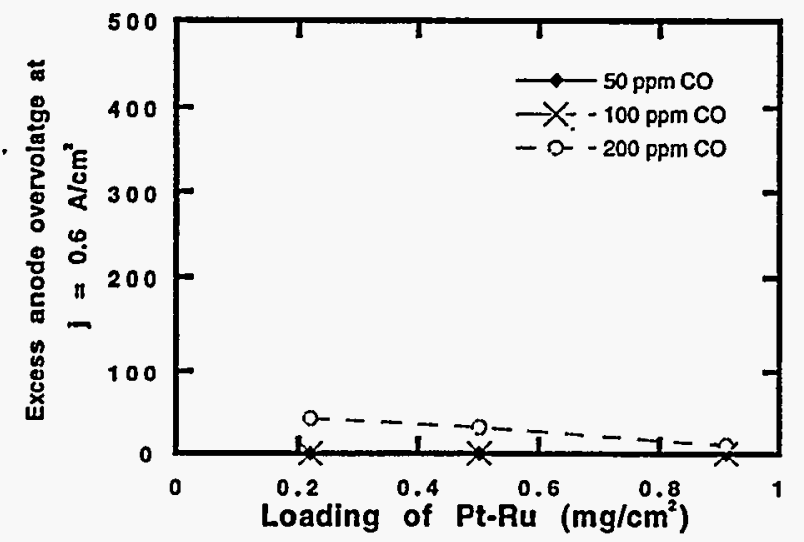

Figure 3. Dependence on Pt-Ru loading of anode loss at $0.6 \mathrm{~A} / \mathrm{cm}^{2}$ in the presence of various levels of $\mathrm{CO}$; cell operating at $120^{\circ} \mathrm{C}$.

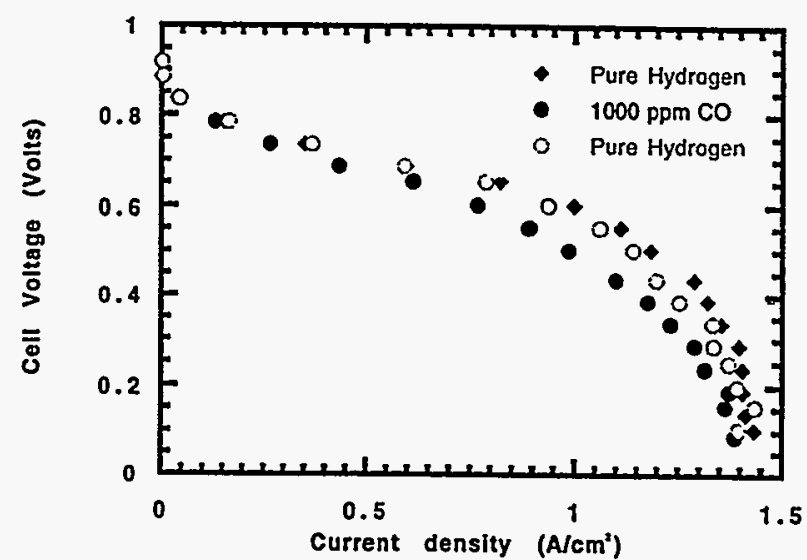

Figure 4. Demonstration of complete tolerance to $1000 \mathrm{ppm} \mathrm{CO}$ in a cell operating at $120^{\circ} \mathrm{C}$ with anode catalyst loading of $1.6 \mathrm{mg} / \mathrm{cm}^{2}$. Runs on pure hydrogen are shown before and after exposure to $\mathrm{CO}$.

\section{Modeling}

We developed a model that adequately describes anode operation on $\mathrm{H}_{2} / \mathrm{CO}$ mixtures. We solved a set of coupled kinetic equations that describe the adsorption and electrochemical reactivity of hydrogen and $\mathrm{CO}$ at a Pt anode catalyst. Appropriate parameters for $\mathrm{T}=80^{\circ} \mathrm{C}$ were selected, and the model was checked against the generic form of the polarization curve for a PEFC operating on $\mathrm{H}_{2} / \mathrm{CO}$ mixtures. Reasonable qualitative agreement was observed.

Model parameters that provided the best fit to the experiment indicate that tolerance to $100 \mathrm{ppm}$ $\mathrm{CO}$ is achieved at $80^{\circ} \mathrm{C}$ on a catalyst surface of high steady state coverage by $\mathrm{CO}$. Hydrogen reacts on the limited number of $\mathrm{CO}$-free sites. Steady-state $\mathrm{CO}$ coverage on $\mathrm{Pt}$ can be lowered by changes of 1-2 orders of magnitude in either the equilibrium constant for $\mathrm{CO}$ adsorption (temperature effect) or the low rate of $\mathrm{CO}$ electrochemical stripping (alloying effect). The resulting decrease of steady state $\mathrm{CO}$ coverage could seem modest (e.g., from $97 \%$ to $90 \%)$, but the $\left(1-q_{c o}\right)^{2}$ dependence brings about large increases in the hydrogen oxidation current. A key finding is that extremely low levels of $\mathrm{CO}$ oxidative stripping from the electrode surface will result in apparently good CO tolerance. 


\section{PUBLICATIONS}

T. A. Zawodzinski, C. Karuppaiah, F. Uribe and S. Gottesfeld, "Aspects of CO Tolerance in Polymer Electrolyte Fuel Cells: Some Experimental Findings," Proceedings of the Symposium on Electrode Processes for Energy Conversion Conversion and Storage IV. To be published by the Electrochemical Society.
T.E . Springer, T. A. Zawodzinski and S. Gottesfeld, "Modeling of Polymer Electrolyte Fuel Cell Performance With Reformate Fuel Feed Streams," Proceedings of the Symposium on Electrode Processes for Energy Conversion Conversion and Storage IV. To be published by the Electrochemical Society.

\section{B. New CO-Tolerant Catalysts}

Philip N. Ross, Jr., Investigator, Materials Sciences Division, Lawrence Berkeley National Laboratory, University of Califormia, Berkeley, CA 94720

(510) 486-6226; fax: (510) 486-5530; e-mail: pnross@lbl.gov

\section{Objectives}

- Conduct research on the kinetics and mechanism of the electrode reactions in low temperature fuel cells and provide the intellectual foundation for the development of new catalysts.

\section{Approach}

- Use ultrahigh vacuum (UHV) methods of surface preparation and surface analysis to form wellcharacterized electrode surfaces.

- Study the kinetics of fuel cell electrode reactions using modem electroanalytical methods.

- Study the mechanisms of the reactions using state-of-the-art, in-situ spectroscopies.

\section{Accomplishments}

- Established, after nearly a decade of research in this program, the general trends in the electrooxidation of $C_{1}^{*}$ molecules on $\mathrm{Pt}_{1-x} \mathrm{M}_{x}$ alloy surfaces with varying $\mathrm{M}$ and $x$.

- Found that $\mathrm{Pt}_{75} \mathrm{Mo}_{25}$ has nearly the same CO-tolerance as $\mathrm{Pt}$-Ru alloy, but has more stable surface composition and may provide better long-term tolerance than $\mathrm{Pt}-\mathrm{Ru}$ alloy.

- Found that $\mathrm{Sn}$ imparts to Ir the same catalytic enhancement for $\mathrm{CO}$ oxidation that it does to Pt. This result suggests: a) bifunctional mechanism of action versus electronic effect; b) Sn may impart this enhancement to all Pt-Group metals; and c) the use of $\mathrm{Sn}$ as a ternary component.

- Proved that Sn promotes the oxidation of "reversibly adsorbed" CO (desorbed upon switching to pure hydrogen or inert gas) on the $\mathrm{Pt} / \mathrm{Ir}$ sites $=\Rightarrow$ positive reaction order in CO partial pressure.

\section{Future Directions}

- Analyze trends in the CO-tolerance of $\mathrm{Pd}_{1-x} \mathrm{M}_{x}$ electrode surfaces with varying $\mathrm{M}$ and $\mathrm{x}$, where $\mathrm{M}$ is $\mathrm{Nb}, \mathrm{Ta}, \mathrm{Mo}$ and $\mathrm{W}$, and $\mathrm{x}$ is 0.1 to 0.25 .

\footnotetext{
* methanol, formic acid, formaldehyde and carbon monoxide
} 
- Determine the CO-tolerance of ternary $\mathrm{Pt}_{1-x \times y} \mathrm{MM}_{x}$ electrodes by plasma immersion ion-implantation (PIII) of Mc in PtM binary alloy. First systems to study are $M=R u, M o$, and $M q=S n$.

Following nearly a decade of research in this program, we have established the general trends in the electrooxidation of $\mathrm{C}_{1}^{*}$ molecules on $\mathrm{Pt}_{1-\mathrm{x}} \mathrm{M}_{\mathrm{x}}$ alloy surfaces with varying $M$ and $x$. These trends can be summarized in the following principles:

a) When there is enhanced activity, the bifunctional action is generally valid: admetal serves to nucleate $\mathrm{OH}$ species on the surface at a lower potential than on $\mathrm{Pt}$; $\mathrm{C}_{1}$ molecules adsorbed preferentially on Pt sites.

b) Intermetallic bonding can change properties of both metals for $\mathrm{OH}_{\text {ads }}$ formation and for $\mathrm{C}_{1}$ adsorption. This effect is most pronounced in highly exothermic alloys; the effect in most others is subtle.

c) An ensemble effect is generally observed for the methanol dehydrogenation step; the surface concentration of $\mathrm{M}$ must be $10-15 \%$ to optimize the rate of this step.

d) Rate of the binuclear reaction between $\mathrm{CO}_{\text {ads }}$ and $\mathrm{OH}_{2 \mathrm{ds}}$ species is the rate-limiting step in most cases; i.e., reactivity of the $\mathrm{OH}_{\text {ads }}$ species is the most important single property.

The electrochemical oxidation of hydrogen $\left(\mathrm{H}_{2}\right)$, carbon monoxide (CO), and their mixtures (500 ppm - $2 \%$ ) on a well-characterized $\mathrm{Pt}_{70} \mathrm{Mo}_{30}$ bulk alloy was examined using the rotating disk electrode technique in $0.5 \mathrm{M} \mathrm{H}_{2} \mathrm{SO}_{4}$ at $333 \mathrm{~K}$. The electrodes were transferred to and from a UHV chamber, where surface analyses were conducted using a combination of low energy ion-scattering (LEIS), Auger electron spectroscopy (AES), and $x-$ ray photoelectron spectroscopy (XPS). The surface composition of this alloy after sputter-etching and annealing in UHV was slightly enriched in $\mathrm{Pt}$ to a composition of $\mathrm{Pt}_{\pi} \mathrm{Mo}_{23}$. The kinetics of $\mathrm{H}_{2}$ oxidation are not measureably affected by the presence of the Mo in the surface.

The shapes of the polarization curves for the the oxidation of the $\mathrm{H}_{2} / \mathrm{CO}$ mixtures are qualitatively similar to those for the $\mathrm{Pt}_{50} \mathrm{Ru}_{50}$ alloy examined previously: a) a high current-potential slope (ca. $0.5 \mathrm{~V} / \mathrm{dec}$ ) at low overpotential, followed by a transition to a highly active state where the current approaches the diffusion-limiting current; $b$ ) the potential where the transition to the active state . occurs decreases with decreasing $\mathrm{CO}$ concentration and decreases with increasing temperature; $c$ ) the current in the low overpotential region is roughly inverse half-order in the $\mathrm{CO}$ partial pressure.

The current densities in the low overpotential region are comparable to those on a $\mathrm{Pt}_{50} \mathrm{Ru}_{50}$ alloy and about a factor of 50 times those on a pure $\mathrm{Pt}$ surface. The anodic stripping of irreversibly adsorbed $\mathrm{CO}\left(\mathrm{CO}_{\text {ads }}\right)$ is, however, very different from that on the $\mathrm{Pt}_{50} \mathrm{Ru}_{50}$ alloy, with most of the $\mathrm{CO}_{\text {ads }}$ being oxidized only above $0.6 \mathrm{~V}$ (reversible hydrogen electrode [RHE]). Also, unlike the $\mathrm{Pt}_{50} \mathrm{Ru}_{50}$ alloy, the currents below $0.6 \mathrm{~V}$ for the continuous Faradaic oxidation of dissolved $\mathrm{CO}$ (gas) are immeasurably small on the $\mathrm{Pt} \mathrm{Mo}_{23}$ surface. The mechanism of action of Mo in the $\mathrm{Pt}$ surface in enhancing $\mathrm{H}_{2}$ oxidation in the presence of $\mathrm{CO}$ thus appears to be fundamentally different from that of Ru.

\section{PUBLICATIONS}

H. Gasteiger, N. Markovic and P. Ross, "A Remarkable Structure Sensitivity in the Electrooxidation of Carbon Monoxide on $\mathrm{Pt}_{3} \mathrm{Sn}$ Alloy Surfaces," Catal. Lett., 36, 1 (1996).

K. Wang, H. Gasteiger, N. Markovic and P. Ross, "On the Reaction Pathway for Methanol and Carbon Monoxide Oxidation on Pt-Sn Versus Pt-Ru Alloy Surfaces," Electrochim. Acta, 41, 2587 (1996).

N. Markovic, H. Gasteiger and P. Ross, "Oxygen Reduction on Platinum Low Index Single Crystal Surfaces in Alkaline Solution: Rotating Ring-Pt(hkl) Disk Studies," J. Phys. Chem., 100, 6715 (1996).

N. Markovic, S. Sarraf, H. Gasteiger and P. Ross, "Hydrogen Electrochemistry on Pt(hkl) Surfaces in Alkaline Solution," J. Chem. Soc., Faraday Trans., 92, 3719 (1996).

A. Widelov, N. Markovic and P. Ross, "Electrochemical and Surface Spectroscopic Studies of Thin Films of Bismuth Ruthenium Oxide $\left(\mathrm{Bi}_{2} \mathrm{Ru}_{2} \mathrm{O}_{7}\right)$," J. Electrochem. Soc., 143, 3504 (1996). 
Fuel Cells for Transportation FY97

N. Markovic, A. Widelov, P. Ross, O. Montiero and I. Brown, "Electrooxidation of $\mathrm{CO}$ and $\mathrm{H}_{2} / \mathrm{CO}$ Mixtures on a Pt-Sn Catalyst Prepared by an Ion-Implantation Method," Catal. Lett., 43, 161 (1997).

N. Markovic, H. Gasteiger and P. Ross, "Kinetics of Oxygen Reduction on Pt(hkl) Electrodes: Implications for the Crystallite Size Effect with Supported Pt Electrocatalysts,"

J. Electrochem. Soc. 144, 1591 (1997).

B. Grgur, G. Zhuang, N. Markovic and P. Ross, "Electrooxidation of $\mathrm{H}_{2} / \mathrm{CO}$ Mixtures on a Well-Characterized $\mathrm{Pt}_{75} \mathrm{Mo}_{25}$ Alloy Surface," J. Phys. Chem. B , 100, 19538 (1996).
N. Markovic, B. Grgur and P. Ross, "TemperatureDependent Hydrogen Electrochemistry on Low-Index Single Crystal Surfaces in Acid Solutions," J. Phys. Chem. B (in press).

H. Gasteiger, N. Markovic and P. Ross, "On the Differences in the Reaction Mechanism for $\mathrm{CO}$ and $\mathrm{CO} / \mathrm{H}_{2}$ Electrooxidation on $\mathrm{PtRu}$ and PtSn Alloy Electrodes," LBNL-40196, UC-1501.

P. Ross, "The Science of Electrocatalysis on Bimetallic Surfaces," LBNL-40486, UC-1501, to be published in Frontiers in Electrochemistry, J. Lipkowski and P. Ross, eds, Vol 4, WileyInterscience, New York, NY (1997).

\section{X-ray Absorption Studies of Catalysts}

James McBreen

DAS, Bldg. 480, Brookhaven National Laboratory, Upton, NY 11973

(516)344-4513, fax: (516)344-4071

\section{Objectives}

- Understand CO poisoning and electrocatalysis at the molecular level.

- Apply results to the development of new catalysts.

\section{Approach}

- Use in situ x-ray spectroscopic methods.

- Perform measurements on real fuel cell catalysts - dispersed supported Pt and Pt alloy catalyst.

\section{Accomplishments}

- Devised in situ methods to observe interaction of $\mathrm{CO}$ with $\mathrm{Pt}$ and $\mathrm{Pt}$ alloy catalysts.

\section{Future Directions}

- Studies of $\mathrm{CO}$ interactions with binary and ternary catalysts.

- Catalyst synthesis and characterization. 
The objective of this program is to understand $C O$ poisoning of anode catalysts at the molecular level and use this information to design $\mathrm{CO}$ tolerant anode catalysts for use with reformate fuel streams. The work focuses on the use of in situ $x$-ray absorption spectroscopy (XAS) to study $\mathrm{CO}$ interactions with supported $\mathrm{Pt}$ and $\mathrm{Pt}$ alloy fuel cell electrocatalysts. Ex situ x-ray diffraction (XRD) was used to determine the lattice constants and the structure of the alloyed catalysts.

Most of our work has been on carbon supported $\mathrm{Pt}, \mathrm{PtSn}, \mathrm{PtRu}$ and PtMo catalysts from ETEK. In addition, some work was done on $\mathrm{Pt}, \mathrm{PtRu}$, and PtSn catalysts supported in a polyaniline (PANI) matrix. These were prepared by Claude Lamy's group at the University of Poitiers. They had found that incorporation of $\mathrm{Pt}$ in PANI induced a negative shift of $100 \mathrm{mV}$ in the oxidation potential for $\mathrm{CO}$ oxidation. ${ }^{1}$

XAS was used to elucidate the effect of alloying elements on the electronic structure and the $\mathrm{Pt}-\mathrm{Pt}$ bond distances. In the case of carbon-supported $\mathrm{Pt}$ $(\mathrm{Pt} / \mathrm{C})$ and $\mathrm{PtSn} / \mathrm{C}$, it was possible to detect the $\mathrm{Pt}-$ $\mathrm{CO}$ interactions, determine $\mathrm{Pt}-\mathrm{C}$ bond distances, and determine the interaction of the $\mathrm{Pt} d$-band electrons with the adsorbed CO. With XAS it was also possible to determine the effect of the alloying element on $\mathrm{OH}$ adsorption on $\mathrm{Pt}$. Also, the effect of potential on $\mathrm{OH}$ adsorption on the alloying element could be determined.

Analysis of the $\mathrm{Pt}_{3}$ and $\mathrm{L}_{2}$ white lines indicated that alloying of $\mathrm{Pt}$ with $\mathrm{Ru}$ increased the $\mathrm{Pt} d$ band vacancies whereas alloying with $S n$ caused a filling of the $\mathrm{Pt} d$ bands. XRD confirmed that both $\mathrm{Ru}$ and $\mathrm{Sn}$ formed a $\mathrm{Pt}_{3} \mathrm{M} \mathrm{L1}_{2}$ superlattice with the $\mathrm{Pt}$. The degree of ordering was greater with the $\mathrm{Pt}_{3} \mathrm{Sn}$ and several superlattice peaks could be seen. Analysis of line broadening indicated that the average particle size was $35 \mathrm{C}$ for both catalysts.

Figure 1 shows the effect of $\mathrm{CO}$ adsorption on the $\mathrm{Pt}_{3} \mathrm{x}$-ray absorption near edge spectrum (XANES). On the absorption of CO, there is an increase in the intensity of the white line. This is due to back donation of $\mathrm{Pt} d$ electrons to $p$ orbitals on the CO. Analysis of the EXAFS indicated a Pt-C bond distance of $2.92 \mathrm{C}$, a value between the $1.85 \mathrm{C}$ for on top $\mathrm{CO}$ and the $2.08 \mathrm{C}$ for bridged bonded $\mathrm{CO}$. This indicates a mix of the two types of $\mathrm{CO}$ on $\mathrm{Pt} / \mathrm{C}$.

The effect of $\mathrm{CO}$ on the $\mathrm{Pt} \mathrm{L}_{3}$ XANES for $\mathrm{PtSn} / \mathrm{C}$ was similar to that seen for $\mathrm{Pt} / \mathrm{C}$. The $\mathrm{Pt}-\mathrm{C}$ interaction was very clear in the EXAFS as can be seen in Figure 2. The $\mathrm{Pt}-\mathrm{C}$ bond distance was $1.8 \mathrm{C}$. The

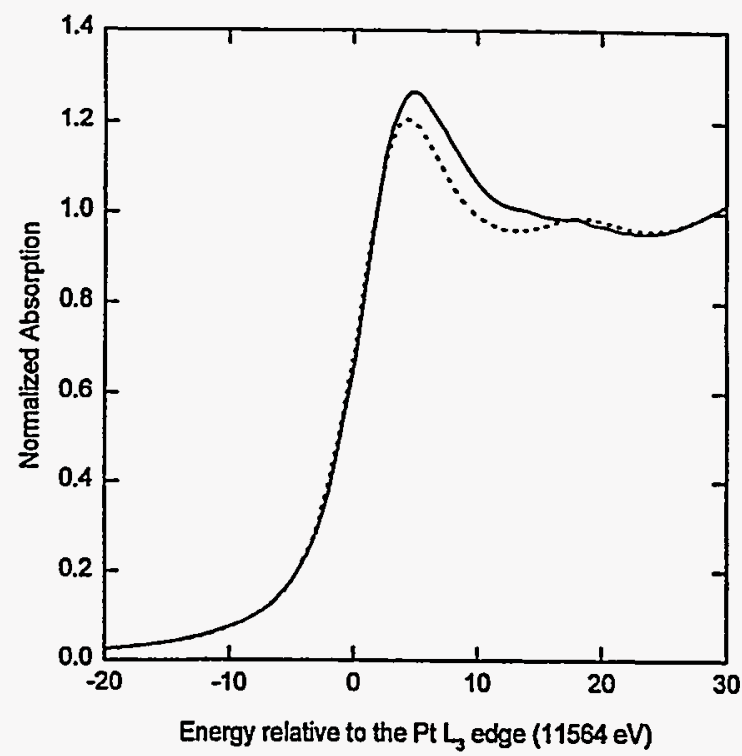

Figure 1. Normalized $\mathrm{Pt} \mathrm{L}_{3}$ XANES for $\mathrm{Pt} / \mathrm{C}$ in $1 \mathrm{M}$ $\mathrm{HClO}_{4}$ at $0.15 \mathrm{~V} \mathrm{RHE}$ with $\mathrm{CO}$ and without $\mathrm{CO}$.

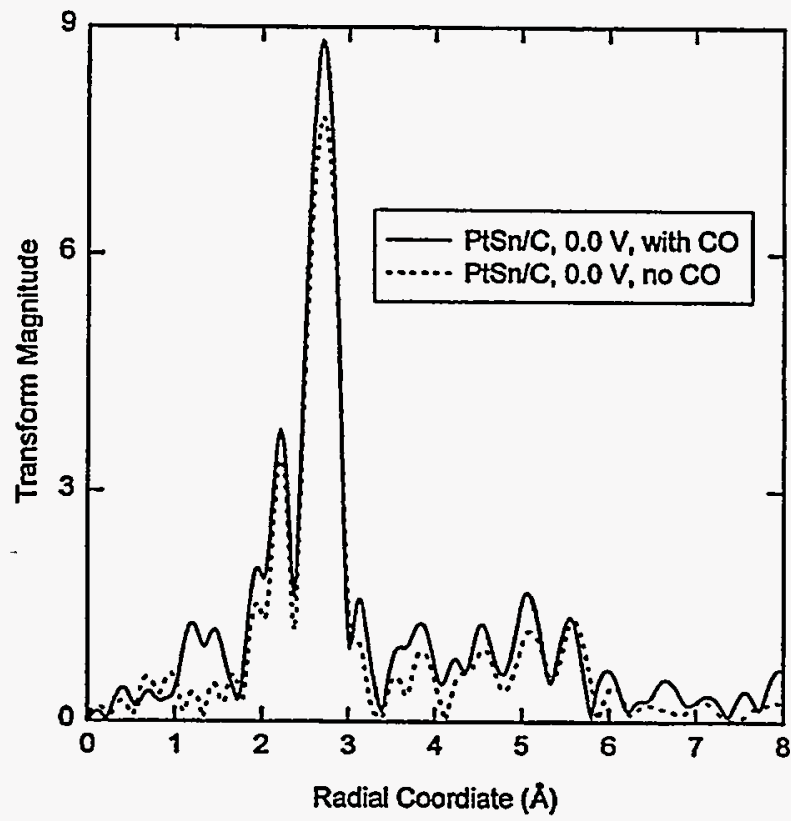

Figure 2. Fourier transform of the $\mathrm{Pt} \mathrm{L}_{3}$ EXAFS for $\mathrm{PtSn} / \mathrm{C}$ in $1 \mathrm{M} \mathrm{HClO}_{4}$ at $0.0 \mathrm{~V} \mathrm{RHE}$ with $\mathrm{CO}$ and without $\mathrm{CO}$; $\mathrm{Pt}-\mathrm{C}$ peak at $1.0-1.7 \mathrm{C}$.

short $\mathrm{Pt}-\mathrm{C}$ bond distance indicates the predominance of top bonded $\mathrm{CO}$ on the $\mathrm{Pt}$ in $\mathrm{PtSn} / \mathrm{C}$.

Unlike $\mathrm{Pt} / \mathrm{C}, \mathrm{PtSn} / \mathrm{C}$, or $\mathrm{PtMo} / \mathrm{C}$, adsorption of $\mathrm{CO}$ had no effect on the $\mathrm{Pt} \mathrm{L}_{3}$ XANES for $\mathrm{PtRu} / \mathrm{C}$. Adsorption of $\mathrm{CO}$ was confirmed by an anodic sweep that yielded a large desorption peak for the $C O$. The reason for this adsorption is unclear, but it may indicate a different type of $\mathrm{CO}$ adsorption on $\mathrm{PtRu} / \mathrm{C}$. Further investigations are underway in conjunction with LANL to elucidate the effect. 
Fuel Cells for Transportation FY97

\section{REFERENCES}

1. W. T. Napporn, J. M. LÇger and C. Lamy, J. Electroanal. Chem., 408, 141 (1996).

\section{PUBLICATIONS}

S. Mukerjee and J. McBreen, "Hydrogen Electrocatalysis by Carbon Supported $\mathrm{Pt}$ and Pt Alloys: An In Situ X-ray Absorption Study," J. Electrochem. Soc., 143, 2285 (1996).

S. Mukerjee and J. McBreen, "Effect of Particle Size on the Electrocatalysis by Carbon Supported Pt Electrocatalysts: An In Situ XAS Investigation," J Electroanal. Chem. (1997), in press.
S. Mukerjee and J. McBreen, "The Effects of Ru and $\mathrm{Sn}$ Additions to $\mathrm{Pt}$ on the Electrocatalysis of Methanol Oxidation: An In Situ XAS Investigation," Proc. $2^{\text {nd }}$. Int. Symp. on New Materials for Fuel Cell and Modern Battery Systems, Montreal, Canada, July 6-10, 1997. O. Savdogo and P. R. Roberge, Eds. (1997), pp. 548-559.

S. Mukerjee and J. McBreen, "Electrocatalysis of Methanol and CO Oxidation: An In Situ XAS Study," Proc. Symp. on Electrode Materials and Processes for Energy Conversion and Storage IV, J. McBreen, S. Mukerjee and S. Srinivasan, Eds., The Electrochemical Society, Inc., Pennington, NJ, (1997), pp. 36-51.

\section{Fuel Cell Electrode Research: CO Bonding to Electrocatalysts}

Elton J. Cairns, Mark S. Yahnke, Benjamin M. Rush and Jeffrey A. Reimer

Environmental Energy Technologies Division, Lawrence Berkeley National Laboratory, Berkeley, CA 94720

(510)486-5028, fax: (510)486-7303

\section{Objectives}

- Develop better electrocatalysts for tolerance and/or oxidation of $\mathrm{CO}$, and for the oxidation of organic fuels.

- Develop nuclear magnetic resonance (NMR) as a technique for the in situ investigation of the identity of electrocatalyst surface species and the bonding of those species to the electrocatalyst surface.

\section{Approach}

- Characterize the surface species resulting from the adsorption of $\mathrm{CO}$ onto $\mathrm{Pt} / \mathrm{C}$ fuel cell electrodes as a function of coverage.

- Compare the coverage and bonding of $\mathrm{CO}$ surface species on various electrocatalysts, including $\mathrm{Pt} / \mathrm{C}, \mathrm{Pt}-\mathrm{Ru} / \mathrm{C}, \mathrm{Pt}-\mathrm{Sn} / \mathrm{C}$, and others.

- Identify unique characteristics of the most active electrocatalysts to serve as a guide in the development of new electrocatalysts.

\section{Accomplishments}

- Identified and characterized $\mathrm{CO}$ adsorbate on a commercial $\mathrm{Pt} / \mathrm{C}$ fuel cell electrode; measured the coverages of bridged and linear bonded forms as a function of total CO coverage.

- Developed the NMR method for application to the study of surface species on conductive elec- trodes. To the best of our knowledge this is the first time that this has been achieved anywhere. 


\section{Future Directions}

- Extend the CO studies to Pt-Ru/C, Pt-Sn/C, and other electrocatalysts.

- Refine the NMR technique to provide for more rapid data acquisition and NMR spectra under current-flow conditions.

The relationship between the kinetics of fuelcell electrode processes and the molecular-level composition and structure of the electrode surface is being investigated. The electrode processes being studied are those occurring in fuel cells operating at relatively low temperatures, including the oxidation of hydrogen-carbon monoxide mixtures and the direct oxidation of methanol. A variety of electrode materials is under investigation, including $\mathrm{Pt}$, binary $\mathrm{Pt}$ alloys such as $\mathrm{Pt}-\mathrm{Ru}$, and $\mathrm{Pt}-\mathrm{Sn}$, supported on carbon, in practical electrode structures. The techniques used involve a combination of modern electrochemical techniques, coupled with our newly-developed NMR method for studying electrodes in situ. The aim of this research is to develop electrode-electrolyte combinations for high-performance fuel cells that operate on hydrogen-carbon monoxide mixtures (highest priority) or directly on methanol (second priority).

The general approach used in these investigations involves studying fuel cell electrodes under realistic cell operating conditions and using modern instrumental techniques to monitor the electrode behavior. In order to identify highperformance electrodes for use in fuel cells, fundamental studies of the electrochemical kinetics of candidate catalyst/electrolyte combinations are performed, including in situ spectroscopic studies to characterize the interfacial region. The use of powerful in situ techniques, including NMR and photothermal deflection spectroscopy (PDS), to identify electrode surface species under realistic fuel-cell operating conditions is a key feature of this research effort. The most promising combinations of electrocatalysts and electrolytes will be evaluated in model cells using porous gas-diffusion electrodes.

The application of NMR to electrocatalytic systems presents major experimental challenges. Paramount among these is dealing with the conflicting requirements of the two systems with regard to sample conductivity. During FY 1997 we made major advances in dealing with the problem of bulk sample conductivity. Through refinement of the electrode-separator structure, the unwanted coupling of the NMR sample to the coil has been virtually eliminated, thereby permitting the acquisition of meaningful NMR spectra under open-circuit conditions and strongly suggesting the possibility of acquiring spectra under conditions of in situ electrode potential control. Using this improved electrode structure, quantitative solidstate NMR spectra of $\mathrm{CO}$ adsorbed from solution onto a commercial fuel-cell electrode material have been acquired. Figure 1 shows representative ${ }^{13} \mathrm{CO}$ NMR data. The upper spectrum shows the sample with saturation coverage of $\mathrm{CO}$, and the lower spectrum shows the same sample with no $\mathrm{CO}$ adsorbed. The latter spectrum is a background signal and is consistent with the known NMR parameters of graphite (the electrode support material) and polytetrafluoroethylene (FTFF, from probe components). The spectra in Figure 2 show background-subtracted data for $\mathrm{CO}$ adsorption at different coverages.

Previously-reported NMR spectra of adsorbed $\mathrm{CO}$ from the gas phase onto supported-Pt particles are broad and featureless. Chemical and Knight shifts account for the observed resonance frequencies, whereas line widths are governed by other factors. While our data appear featureless at high coverages, they undergo significant changes as surface coverage decreases; indeed at low coverages, the observed line shape is well fit to a

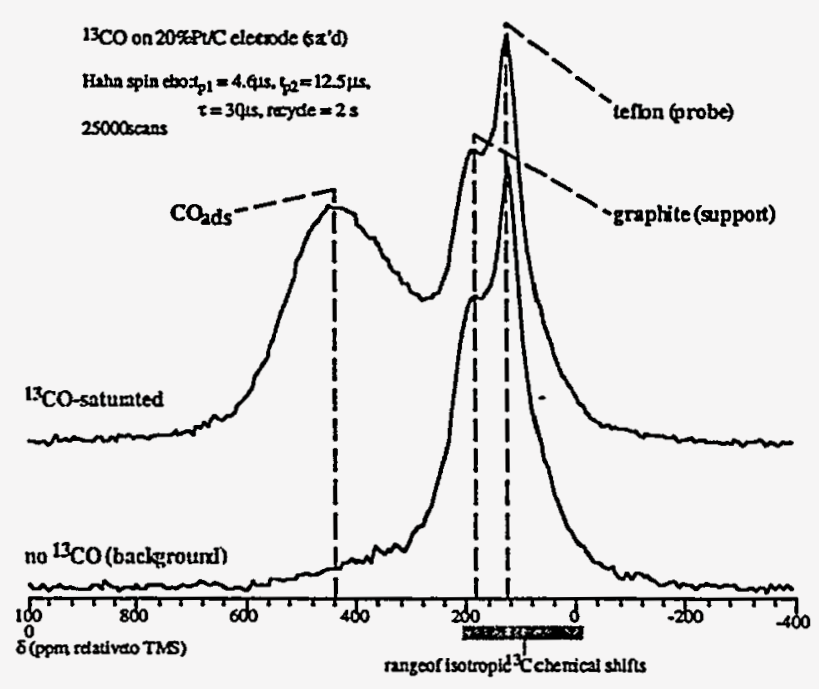

Figure 1. NMR spectrum of saturated $\mathrm{CO}$ on $\mathrm{Pt} / \mathrm{C}$, and background. 


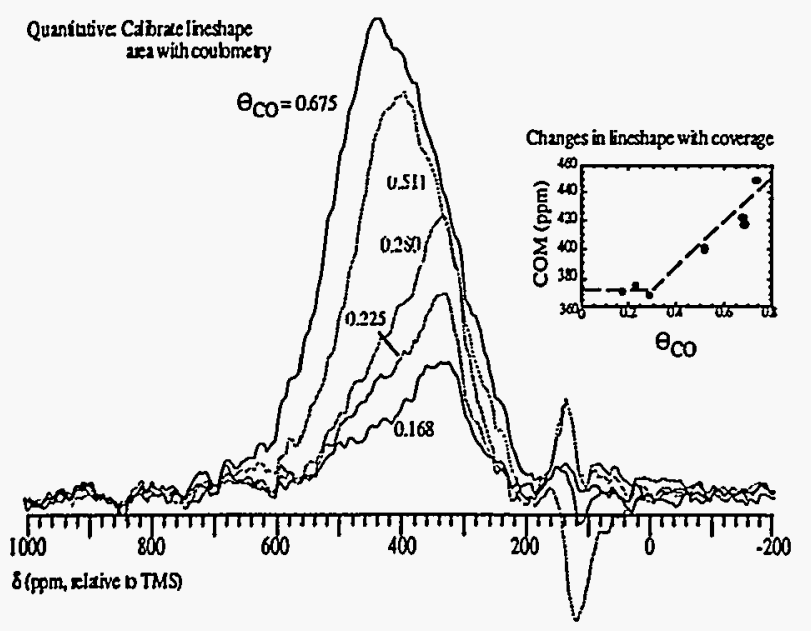

Figure 2. Background-subtracted NMR spectra for various $C O$ coverages.

chemical shift powder pattern having an anisotropy of about $100 \mathrm{ppm}$, virtually identical to the anisotropies reported for bridge-bonded $\mathrm{CO}$ on supported Ru and Rh particles. Thus our observations appear to be consistent with changing populations of linear and bridge-bonded $\mathrm{CO}$ with surface coverage. Additional detail and interpretation were presented at the Fuel Cell Contractors' Review Meeting, July 22-23, 1997.

Additional experiments are in progress on $\mathrm{CO}$ adsorption and oxidation on carbon-supported $\mathrm{Pt}$, $\mathrm{Pt}-\mathrm{Ru}$, and $\mathrm{Pt}-\mathrm{Sn}$. A few exploratory experiments are being carried out on methanol using the above electrocatalysts.
We have also made some significant improvements in the experimental apparatus to provide large reductions in data acquisition time. These include a higher-field magnet (9T vs. 6.4T), denser electrode packing, double-sided electrodes, more electrocatalysts per unit support area, and the ability to perform electrochemical measurements while the cell is in the NMR magnet.

\section{PUBLICATIONS}

M. S. Yahnke, B. M. Rush, J. A. Reimer and

E. J. Cairns, "Quantitative Solid-State NMR Spectra of CO Adsorbed from Aqueous Solution onto a Commercial Electrode," J. Am. Chem. Soc., 118(48), 12250 (1996).

M. S. Yahnke, J. A. Reimer and E. J. Cairns, "The Application of Solid-State NMR Spectroscopy to Electrochemical Systems: CO Adsorption on $\mathrm{Pt}$ Electrocatalysts at the Aqueous-Electrode Interface," M.S. Thesis, LBNL-39802 (1996).

M. L. Perry, F. R. McLarnon, J. S. Newman and E.J. Cairns, "Exploratory Fuel-Cell Research: I. Direct-Hydrocarbon Polymer-Electrolyte Fuel Cell. II. Mathematical Modeling of FuelCell Cathodes," M.S. Thesis, LBNL-39803 (1996).

M. L. Perry, J. Newman and E. J. Cairns, "Mass Transport in Gas-Diffusion Electrodes: A Diagnostic Tool for Fuel-Cell Cathodes," submitted J. Electrochem. Soc., LBNL-40139 (1997).

\title{
E. Bipolar Plate Materials Development
}

\author{
Mahlon S. Wilson \\ MS D429, Materials Science and Technology Division \\ Los Alamos National Laboratory, Los Alamos, NM 87545 \\ (505) 667-6832, fax: (505) 665-4292
}

\section{Objectives}

- Develop low-cost, readily mass-producible composite bipolar plates with the requisite combination of material properties. Target cost for finished plates is $\$ 10 / \mathrm{kW}$.

\section{Approach}

- Develop compression moldable composites based on low-cost, non-conductive milled microfibers, graphite powders, and thermoset binders. 
- Investigate the viability of milled metal fiber composites.

\section{Accomplishments}

- Obtained either high electronic conductivities or low permeabilities using low-cost, non-conductive fibers and thermoset resins.

\section{Future Directions}

- Identify and investigate appropriate binders and fibers to maximize plate performance.

- Demonstrate full-scale plates.

While cost is the most important challenge for new bipolar plate technologies, transportation applications additionally require that the plates be lightweight, tough, and somewhat flexible to enable the use of thin unit cells to meet power density goals. Additionally, the plates must have a high conductivity as well as possess the low permeability and corrosion tolerance provided by the machined graphite or Kynar/graphite composite mainstays of the technology.

While a number of approaches may potentially meet these challenges, we chose to investigate molded composites because they tend to be corrosion resistant and light weight, and molding is a well established mass-production process. While injection molding typically provides the highest production rates and lowest costs, the poor rheological characteristics of the high solids content compounds (needed to attain high conductivities with non-metallic components) invariably require the use of compression molding. The combination of such high solids contents with the very low porosities required results in a relatively brittle part that is easily cracked if subjected to even minor deformation in the stack. Thus, we attempt to improve the mechanical properties using fibers. The use of fiber reinforcements in composites is, of course, not new, but they historically have been used either in the form of a fabric mat or, at best, a relatively long chopped fiber. In order to attain a relatively homogenous and complete fill in the rather complicated and intricate plate designs that tend to be used for the bipolar plate flow-fields, we use milled micro-fibers that are shorter than the mold features.

This approach builds on our recent efforts investigating composites based on milled carbon micro-fibers, graphite powder, and Kynar (polyvinylidene fluoride [PVDF]). A small group- ing of formulations were identified that provided the desired properties as well as high out-of-themold surface conductivities. Small 2-mm thick disks with molded-in flow-fields were formed and tested in fuel cells for up to $500 \mathrm{~h}$, one of which is depicted in Figure 1. The figure also shows that an effective fill of the relatively fine structures is accomplished.

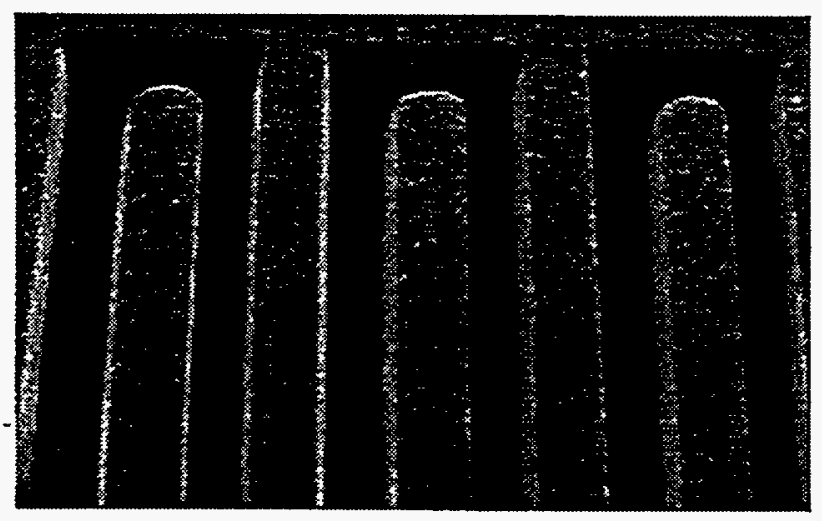

Figure 1. Micrograph of a milled carbon-fiber composite plate flow-field. Height, width and spacing of channels $=0.8 \mathrm{~mm}$ (0.032 in.).

While these carbon fiber/Kynar results are promising, milled carbon fibers and Kynar may be too expensive to meet Partnership for a New Generation of Vehicles (PNGV) cost goals, even in large-scale production quantities. Kynar costs on the order of $\$ 8 / \mathrm{lb}$ in railcar quantities and milled carbon fiber is unlikely to ever cost less than $\$ 10 / \mathrm{lb}$. Since the PNGV goals suggest that the finished plates will need to cost on the order of $\$ 10 / \mathrm{kg}(\$ 4.50 / \mathrm{lb})$, replacement materials need to be identified. Another difficulty with the use of Kynar (or any thermoplastic) in a compression molding process is that the part needs to be cooled 
in the mold under pressure, which results in long cycle times.

The cost and production considerations require new strategies. The first of these are to replace the milled carbon fibers with less expensive alternatives. As it is, the contribution of the carbon fiber to the sample conductivity is marginal, the graphite powder provides the electronic continuity. Thus, the use of much less expensive nonconductive fibers may provide the desired mechanical properties without sacrificing conductivity.

Following the lead of Spectracarb Corp., cycle times can be decreased to minutes instead of hours in the compression molding process with the use of thermoset instead of thermoplastic binders. The rheologies of the mixtures also appear to improve with the relatively low-viscosity nonreacted thermosets. The last component of the new strategies is that the use of nonconductive binders and thermoset resins opens up the possibilities of attaining direct chemical bonds between the two components for enhanced strength.

A modest number of thermoset composites with nonconductive fibers has been prepared. Table 1 illustrates that either very low permeabilities or very high conductivities can be readily attained. While the elongation before failure is very poor, the thermoset used for these formulations was itself very brittle, and more appropriate binders need to be investigated.

Despite the brittleness, the cross-linking thermoset provided a very tough sample that was difficult to break.

Continuing with some work done last year, a number of composite samples were prepared using relatively low-volume fractions of metal fibers. In contrast to the aforementioned case with the carbon fibers, high conductivities are obtained with these samples in the absence of graphite powder. The high polymer contents not only provide excellent mechanical properties, but there is a possibility that such composites may be injection moldable. As mentioned above, such a process is ideal for mass production from a processing point of view. While corrosion of the metal fibers is an important issue, work here (for the Hydrogen Program) and elsewhere suggests that there is a possibility that untreated metal alloys may be sufficiently corrosion resistant. While the cost of the metal fibers could be problematic, the low processing costs may offset the higher material costs. Several compression-molded samples with metal fibers were prepared, two of which are depicted in Table 2. Once again, it is shown that very good values of any one (or two) of the merit properties are readily attained, but the identification of the ideal formulations and processes will require further effort.

Table 1. Samples with nonconductive fibers.

\begin{tabular}{|c|c|c|c|}
\hline Material & $\begin{array}{c}\text { Bulk Conductivity } \\
(\mathrm{S} / \mathrm{cm})\end{array}$ & $\begin{array}{c}\text { Permeability } \\
\left(\mathrm{mA} / \mathrm{cm}^{2} \mathrm{H}_{2} \text { equiv., } 1\right. \\
\text { mm thick sample) }\end{array}$ & $\begin{array}{c}\text { Elongation before } \\
\text { Failure (\%) }\end{array}$ \\
\hline Composite "A" & $26-30$ & 0.005 & $1.5-1.6 \%$ \\
\hline Composite "B" & $172-191$ & 0.21 & $1.1-1.2 \%$ \\
\hline
\end{tabular}

Table 2. Samples with metal fibers.

\begin{tabular}{|c|c|c|c|}
\hline Material & $\begin{array}{c}\text { Bulk Conductivity } \\
(\mathrm{S} / \mathrm{cm})\end{array}$ & $\begin{array}{c}\text { Permeability } \\
\left(\mathrm{mA} / \mathrm{cm}^{2} \mathrm{H}_{2} \text { equiv., } 1\right. \\
\text { mm thick sample) }\end{array}$ & $\begin{array}{c}\text { Elongation before } \\
\text { Failure (\%) }\end{array}$ \\
\hline Composite "C" & $276-406$ & $>1$ & $7 \%$ \\
\hline Composite "D" & $25-27$ & 0.002 & $>10 \%$ \\
\hline
\end{tabular}




\title{
F. Bipolar Plate Materials Development
}

\author{
T. M. Besmann, J. W. Klett and T. D. Burchell
}

MS 6063, Oak Ridge National Laboratory, P.O. Box 2008, Oak Ridge, TN 37830-6063

(423)574-6852, fax: (423)574-6918, e-mail: tmb@ornl.gov

\section{Objectives}

- Develop a slurry molded carbon fiber material with a carbon chemical vapor infiltrated sealed surface as a bipolar plate.

- Obtain information from potential manufacturers with regard to the manufacturability of such components.

\section{Approach}

- Fabricate fibrous component preforms for the bipolar plate by slurry molding techriques using carbon fibers of appropriate lengths and particulates.

- Fabricate one side of the plate as hermetic using filler and a final seal with chemical vapor infiltrated carbon.

- Evaluate 25-mm diameter disks at Los Alamos National Laboratory (LANL) for permeability and conductivity.

\section{Accomplishments}

- Prepared slurry molded preforms with minimal porosity on one side via phenolic resin treatment.

\section{Future Directions}

- Complete sealing of high density surfaces via chemical vapor infiltration.

- Provide specimens to LANL for evaluation.

- Scale-up successful processing to full-scale plates.

- Evaluate cost of manufactured plates with material processor.

- As necessary, explore lower cost materials/processing approaches.

Fibrous component preforms for the bipolar plate were prepared by slurry molding techniques using carbon fibers of appropriate lengths and particulates. The approach is such that a two-step vacuum molding process first produces a high density, fine porosity surface followed by molding of the lower density, porous region. A binder is used to provide green strength, and which also assists in providing geometric stability after it is carbonized. The high density surface of the preform will be sealed using a carbon vapor infiltra- tion (CVI) technique in which carbon is deposited on the near-surface fibers sufficient to make the surface hermetic. This is accomplished by placing the preforms in a furnace which is heated 800-1300 $\mathrm{EC}$ and through which a hydrocarbon-containing gas at reduced pressure is allowed to flow over the component. The hydrocarbon reacts and deposits carbon on the exposed fibers of the preform, and, when sufficient deposition has occurred, the surface becomes sealed. Thus, the infiltrated carbon provides both an impermeable surface as 
well as the necessary electrical conductivity so that power can be obtained from the cell.

Initial planar preform sample disks $25 \mathrm{~mm}$ in diameter have been produced that are equal to or less than $2 \mathrm{~mm}$ in thickness. A variety of compositional combinations of fibers and filler have been prepared for evaluation and surfaces sealed by CVI. At least six specimens are being provided to LANL (by Dr. Mahlon Wilson) for permeability and electrical resistivity measurements. Hydrogen permeability is measured by applying a pressure to one side of the component and collecting the transmitted hydrogen by water displacement. The bulk conductivity is being measured by a four point probe. If possible, contact resistances at bipolar plate/electrode contacts in a complete "cell sandwich" configuration are being made to evaluate the overall plate resistivity (bulk + contacts) from total cell high-frequency $(5-10 \mathrm{kHz})$ impedance. One or more potential carbon fiber component manufacturers are being contacted with regard to the manufacturability of the proposed bipolar plate.

\section{G. Effective Cell \& Stack Humidification}

Mahlon S. Wilson

Materials Science and Technology Division, MST-11, MS D429

Los Alamos National Laboratory, Los Alamos, NM 87545

(505) 667-6832, fax: (505) 665-4292

\section{Objectives}

- Develop a high performance, simple, low parasitic power fuel cell system.

\section{Approach}

- Utilize direct liquid water hydration of the membrane/electrode assemblies (MEAs).

- Operate the cathodes at near ambient pressures to minimize parasitic losses.

\section{Accomplishments}

- Demonstrated a roughly 400-W system with less than $3 \%$ parasitic power loss.

- Attained stack power densities of $1 \mathrm{~kW} / \mathrm{L}$ on an active volume basis and $0.6 \mathrm{~kW} / \mathrm{L}$ on an overall plate volume basis.

\section{Future Directions}

- Scale-up further (e.g., ca. $300 \mathrm{~cm}^{2}$ active area, $>4 \mathrm{~kW}$ total power).

- Refine and optimize system, stack components, and operation/control.

The technique of using direct liquid hydration of the MEAs has a number of advantages for a simple, low-cost fuel cell system in that it utilizes "ordinary" MEAs and bipolar plate materials and eliminates the need for a number of auxiliary components. The approach supplies liquid water to all regions of the MEA to improve performance at higher stack temperatures and/or at lower cathode air pressures. Direct liquid hydration also separates the functions of gas supply and membrane hydration, which substantially simplifies the overall system as well as its control. The direct 
liquid hydration of the MEA is accomplished by the placement of special hydrophilic conduits in the "composite" anode gas diffusion backing located over water-filled channels in the anode flow-field.

From a system perspective, the decision was made early this year to concentrate on an ambient pressure system because, compared to more conventional, pressurized systems, replacing the compressor/expander and cooling systems with a single blower substantially decreases costs, complexity, and parasitic power losses. The latter factor is of particular significance because a pressurized fuel cell system may have parasitic power losses as high as $20 \%$, which significantly decreases the overall system efficiency.

The direct liquid method of hydrating the system has advantages at ambient pressure because it is not necessary to humidify the air stream. Since humidifier modules are not required, it is possible to use high air flow rates (stoichiometric flow) with minimal difficulty. In addition, the use of high stoichiometric flow combined with an initially dry airstream serves to maximize the partial pressure of oxygen and, hence, the cathode performance. Lastly, a high air flowrate minimizes the collection of condensate in the flow-field, which greatly simplifies flow-field design and performance because one of the greatest difficulties in conventional designs is accommodating the twophase flow.

Our general development strategy was to attain good ambient pressure performance and demonstrate the viability of the "system" approach on the $100-\mathrm{cm}^{2}$ single-cell level. This gave us an opportunity to refine the anode $\mathrm{H}_{2} / \mathrm{H}_{2} \mathrm{O}$ flow-field designs as well as the composite anode backing construction. Once a design with favorable performance was identified, the composite anode fabrication process was automated and a 12-cell stack was assembled using $1 / 8$ " thick machined commercial graphite/epoxy composite plates. Difficulties were initially encountered with cracking plates, so the MEAs underwent several assembly/disassembly iterations. Figure 1 depicts a polarization curve of this 12-cell stack and system. While the relatively well-worn MEAs did not collectively provide a very good open circuit voltage (OCV), the stack provided better performance at higher current densities (e.g., $600 \mathrm{~mA} / \mathrm{cm}^{2}$ at $0.5 \mathrm{~V} / \mathrm{cell}$ ). It should be pointed out that this performance is obtained at an ambient pressure of only $0.76 \mathrm{~atm}$, as our laboratory is at a high altitude. The parasitic power loss of the system was about $2.5 \%$ at maxi-

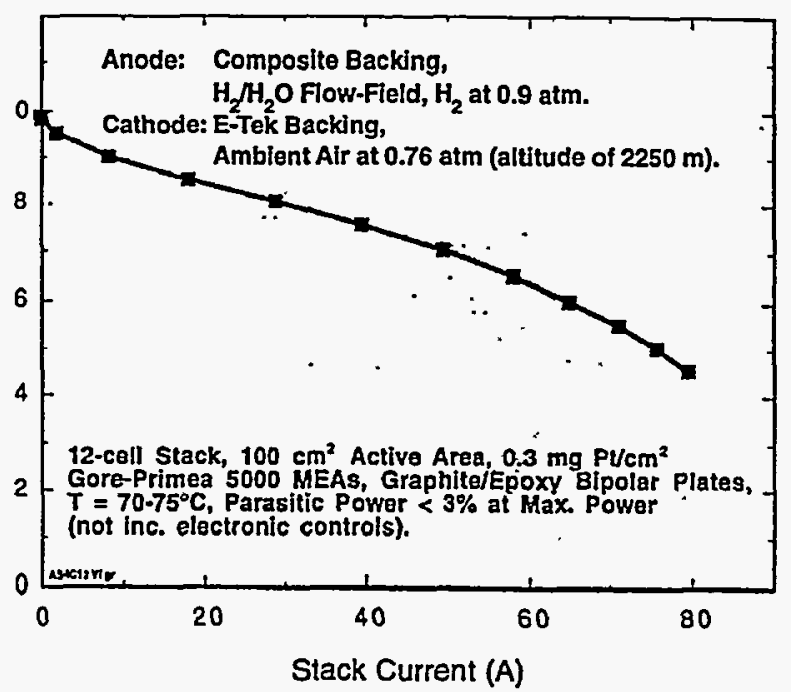

Figure 1. Polarization curve for a 12-cell stack and system.

mum power, not including the electronic controls. While rheostats were used here, chopper-type DC motor controllers are typically over $80 \%$ efficient. In general, the 12-cell stack and system worked well, but difficulties were encountered sealing between the $\mathrm{H}_{2}$ and $\mathrm{H}_{2} \mathrm{O}$ regions on the anode plates. As a result, it was necessary to balance the relative pressures of the two networks, which led to problems with stack stability. Individual cells within the stack would occasionally fail due to lack of water. It was apparent that the anode plate design, which worked well on the single cell level, did not fare so well when there was inter-cell competition. Therefore, several single cells with new anode plate designs were tested. Once the most promising adaptation was identified, the remaining plates from our original 30-plate order were machined with the new design and an 8-cell stack was assembled.

The advantages with the new design were quickly apparent. A polarization curve of the 8-cell stack is provided in Figure 2. The cells on average provided nearly $800 \mathrm{~mA} / \mathrm{cm}^{2}$ at $0.5 \mathrm{~V} /$ cell and the low current density performance was much improved over the 12-cell stack, although the latter results were for MEAs with several iterations on them. The parasitic losses were $3.5 \%$ at maximum power, which was higher than the 12-cell because the blower was not as effective at the lower air flow rate. A comparison of the power densities of the two stacks at "cruise" and maximum power is shown in Table 1. Depending on the criteria used for the calculation, the stack in the 8-cell system provided a maximum volumetric power density of over $1 \mathrm{~kW} / \mathrm{L}$. 
Fuel Cells for Transportation FY97

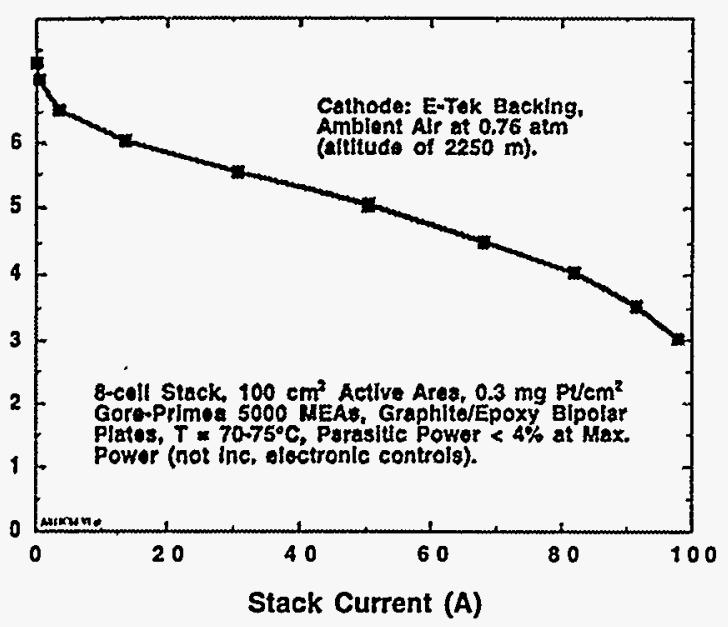

Figure 2. Polarization curve for the 8-cell stack and system with an improved anode plate design.

Table 1. Power densities of the two stacks.

\begin{tabular}{|c|c|c|c|c|}
\hline Stack & $\begin{array}{c}\text { Plate Area } \\
\text { @ 0.7 V/cell } \\
\left(\mathrm{W} / \mathrm{cm}^{3}\right)^{\mathrm{a}}\end{array}$ & $\begin{array}{c}\text { Active Area } \\
@ 0.7 \mathrm{~V} / \text { cell } \\
\left(\mathrm{W} / \mathrm{cm}^{3}\right)^{\mathrm{b}}\end{array}$ & $\begin{array}{c}\text { Plate Area } \\
\text { @ 0.5 V/cell } \\
\left(\mathrm{W} / \mathrm{cm}^{3}\right)^{\mathrm{a}}\end{array}$ & $\begin{array}{c}\text { Active Area } \\
\text { @ 0.5 V/cell } \\
\left(\mathrm{W} / \mathrm{cm}^{3}\right)^{\mathrm{b}}\end{array}$ \\
\hline $12-$ Cell & 0.22 & 0.36 & 0.52 & 0.85 \\
\hline 8 -Cellc & 0.26 & 0.43 & 0.62 & 1.02 \\
\hline
\end{tabular}

a - Considers full bipolar plate area (end-plates not included).

$\mathrm{b}$ - Considers active area, not manifold or sealing areas (end-plates not included).

c - Ambient pressure (0.76 atm) stacks $w / 100-\mathrm{cm}^{2}$ active area using graphite/epoxy plates. 


\section{FUEL PROCESSING}

\section{A. Fuel Processor Development}

\section{Shabbir Ahmed, Sheldon H. D. Lee, Rajiv Doshi, Ira Bloom, Romesh Kumar and Michael Krumpelt} Argonne National Laboratory, Argonne, IL 60439-4837

(630) 252-4553, fax: (630) 252-4176

\section{Objectives}

- Design, develop, and demonstrate on-board fuel processors for light-duty vehicles powered by fuel cells based on catalytic partial-oxidation reforming of fuel.

\section{Approach}

- The reformer development is being pursued at three reactor levels:

- The micro-reactor is used to evaluate and advance catalyst formulations.

- The bench reactor $(1.8 \mathrm{~L})$ is used to verify self-sustained operation.

- The prototype reactor is designed from bench-scale operating experience to meet end use needs.

\section{Accomplishments}

- Developed a new class of partial-oxidation catalyst materials that has demonstrated the ability to convert gasoline into a hydrogen-rich gas in the micro-reactor setup.

- Attained a product gas containing over $90 \%$ of the theoretically available hydrogen at temperatures of $\sim 760^{\circ} \mathrm{C}$.

- Fabricated a prototype $(2.5 \mathrm{~L})$ reactor.

\section{Future Directions}

- The catalyst development work will continue to achieve similar or better performance at lower temperatures.

- The catalyst will be evaluated in the bench reactor to determine performance under the varying thermal conditions typical of reformers.

- The prototype reactor will be tested with methanol and gasoline.

- Various start-up protocols will be tested to achieve operating temperatures in less than 1 minute. 
The objective of this work is to develop fuel processors for use with fuel cell systems in lightduty vehicles. Such fuel processors should have rapid-start and dynamic response capabilities. Partial oxidation reformers, which require no indirect heat transfer, have the best potential to meet these needs. ${ }^{1}$ Our work has been directed at catalytic partial-oxidation reforming because catalytic processes offer product selectivity and high activity at relatively low temperatures.

Three types of liquid fuels have been studied in the past year: gasoline, ethanol, and methanol. Gasoline is a liquid fuel with an existing refueling infrastructure. Therefore, its use will ease the transition of fuel cell vehicles into the market. Ethanol and methanol are liquid fuels that are produced domestically and therefore important from the standpoint of energy security. These alcohols have a high hydrogen-to-carbon atomic ratio, producing less carbon dioxide than petroleum-derived fuels, and are thus considered to be environmentally friendly fuels.

The idealized reaction stoichiometry for the partial-oxidation reforming of a hydrocarbon or alcohol fuel $\left(\mathrm{C}_{n} \mathrm{H}_{m} \mathrm{O}_{\mathrm{p}}\right)$ can be represented by the equation:

$$
\begin{gathered}
\mathrm{C}_{n} \mathrm{H}_{\mathrm{m}} \mathrm{O}_{p}+x\left(\mathrm{O}_{2}+3.76 \mathrm{~N}_{2}\right)+(2 n-2 x-p) \mathrm{H}_{2} \mathrm{O} 6 \\
\mathrm{nCO}_{2}+(2 n-2 x-\mathrm{p}+\mathrm{m} / 2) \mathrm{H}_{2}+3.76 x \mathrm{~N}_{2}
\end{gathered}
$$

where $x$ is the oxygen-to-fuel molar ratio. The theoretical concentration of hydrogen ( $\mathrm{vol} \%$ ) in the product gas is then given by

$$
\begin{aligned}
\mathrm{H}_{2, \max }= & (2 \mathrm{n}-2 x-\mathrm{p}+\mathrm{m} / 2)^{*} 100 / \\
& {[\mathrm{n}+(2 \mathrm{n}-2 x-\mathrm{p}+\mathrm{m} / 2)+3.76 x] }
\end{aligned}
$$

Gasoline is a blend of different types of hydrocarbons such as paraffins, olefins, and aromatics. As such, the reforming catalyst should be able to convert the different structures of the hydrocarbon molecules into hydrogen and carbon dioxide. Among the many other requirements of this catalyst, it must not coke - a common problem encountered in hydrocarbon processing; it should resist poisoning by contaminants (e.g., sulfur is present in hydrocarbon fuels and is known to poison a number of catalyst materials); and it should work at low temperatures. Low-temperature operation is important for on-board reforming because hotter processes take longer and consume more fuel during start-up, they limit the choice of materials of construction, and they reduce conversion efficiencies (defined as the lower heating value of the hydrogen in the product gas as a percentage of the lower heating value of the fuel feed).

A new class of catalyst has been developed that has shown very good performance in the conversion of gasoline and its component hydrocarbons in a micro-reactor setup (Fig. 1). The vaporized fuel and water were mixed with oxygen and passed over $2 \mathrm{~g}$ of the catalyst in a micro-reactor (12-mm dia.). The catalyst and the reactor were maintained at the desired temperature by placing them inside a tube furnace. The product gases were analyzed using a gas chromatograph. The catalyst was first tested with pure hydrocarbons to represent the different types of hydrocarbons. present in gasoline. Figures 2 and 3 show the product gas compositions obtained when the Argonne catalyst was tested with iso-octane (as a surrogate for paraffins) and cyclohexane (surrogate for naphthenes). The figures show that the product gas contained $60 \%$ hydrogen at $630^{\circ} \mathrm{C}$ and $700^{\circ} \mathrm{C}$

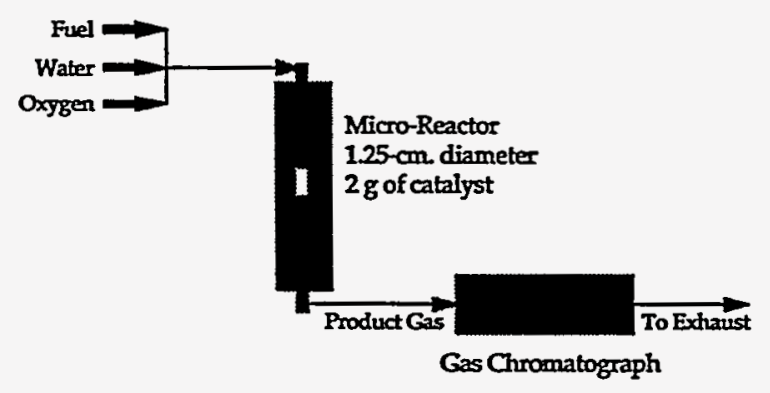

Figure 1. Block diagram of the micro-reactor apparatus used for catalyst testing.

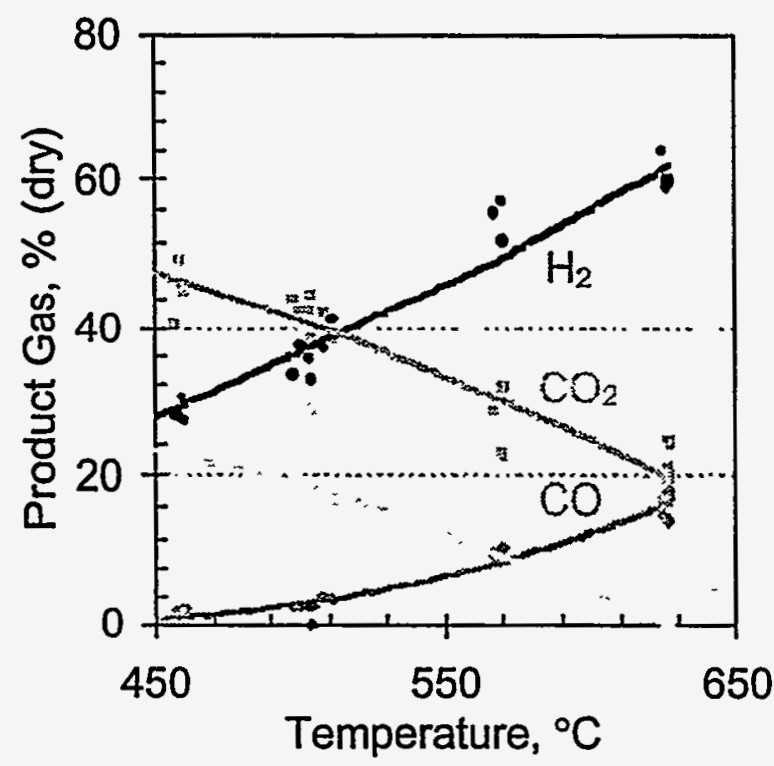

Figure 2. Product gas composition obtained from the partial-oxidation reforming of iso-octane. 
Fuel Cells for Transportation FY97

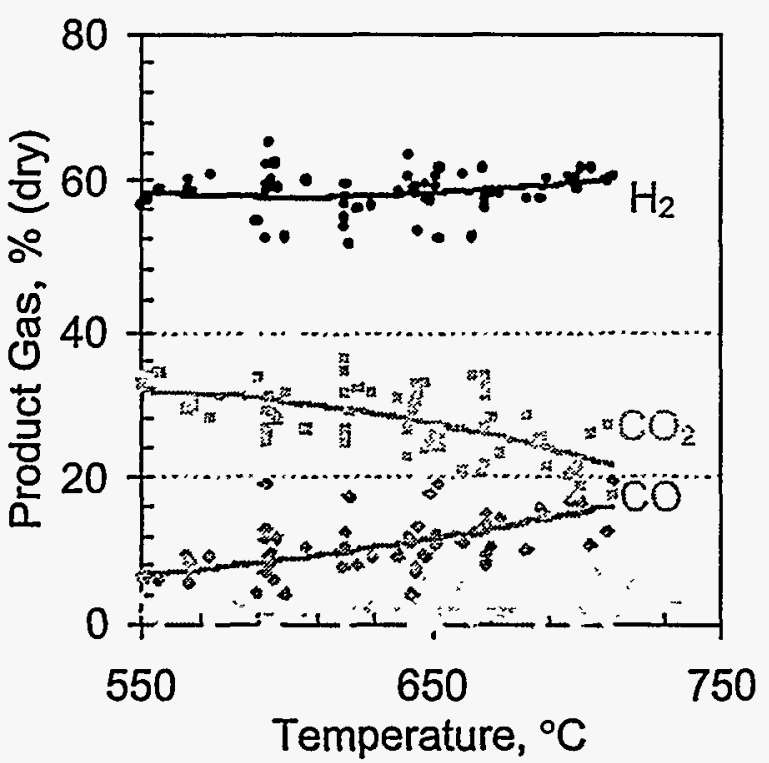

Figure 3. Product gas composition obtained from the partial-oxidation reforming of cyclohexane.

with iso-octane and cyclohexane, respectively. The hydrogen selectivity, defined as:

$\mathrm{H}_{2}$ Selectivity $=\left(\mathrm{H}_{2}\right.$ in Product, \% $) \mathrm{H} 100 /$

(Theoretical Maximum $\mathrm{H}_{2}$ in Product Gas, \%)

was $87 \%$ with iso-octane at $630^{\circ} \mathrm{C}$, and $91 \%$ with cyclohexane at $700^{\circ} \mathrm{C}$.

Similar tests with other hydrocarbon fuels were also performed, and the results are shown in Table 1. For the various fuels, the table shows the reaction temperature, the concentrations of hydrogen and carbon monoxide in the product gas, and the hydrogen selectivity at the given temperature. The hydrogen selectivity ranged between $82 \%$ for toluene and $91 \%$ for cylcohexane.

The catalyst was also tested with regular and premium retail gasolines. Figure 4 shows the product gas composition obtained from premium gasoline with the Argonne catalyst as a function of temperature. The figure shows that at $750^{\circ} \mathrm{C}$,

Table 1. Product gas composition obtained from the partial-oxidation reforming of compounds.

\begin{tabular}{|l|c|c|c|c|}
\hline & $\begin{array}{c}\text { Temp } \\
{ }^{\circ} \mathrm{C}\end{array}$ & $\begin{array}{c}\mathrm{H}_{2} \\
\%\end{array}$ & $\begin{array}{c}\mathrm{CO} \\
\%\end{array}$ & $\begin{array}{c}\mathrm{H}_{2} \\
\%\end{array}$ \\
\hline i-Octane & 630 & 60 & 18 & $87 \%$ \\
\hline Toluene & 655 & 50 & 14 & $82 \%$ \\
\hline 2-Pentene & 670 & 58 & 15 & $87 \%$ \\
\hline Cyclohexane & 700 & 61 & 16 & $91 \%$ \\
\hline Ethanol & 580 & 62 & 15 & $87 \%$ \\
\hline
\end{tabular}

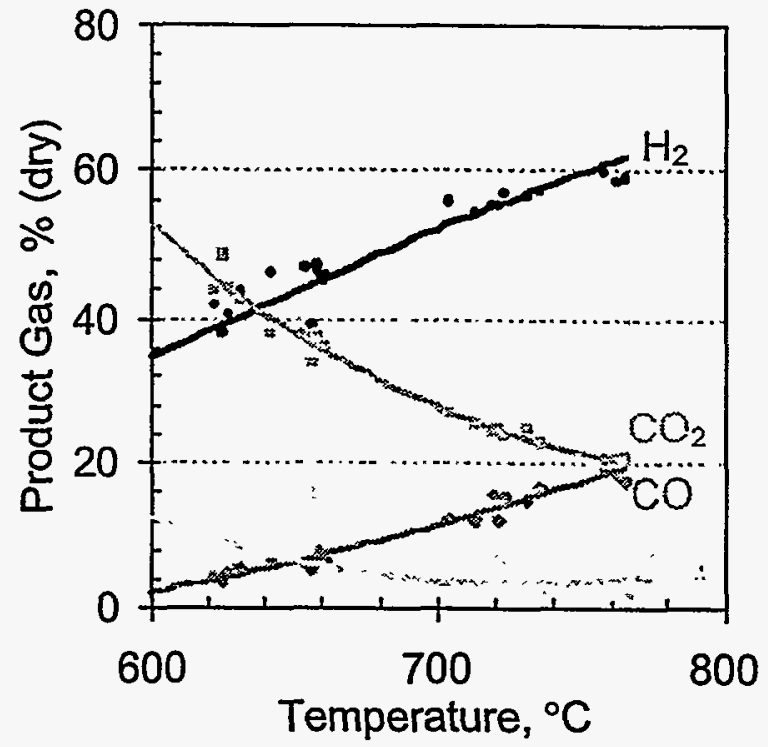

Figure 4. Product gas composition obtained from the partial-oxidation reforming of premium gasoline.

$60 \%$ hydrogen was observed in the product gas, together with $20 \%$ carbon dioxide, $18 \%$ carbon monoxide, and $2 \%$ methane. The gasoline sample was analyzed and found to have an average composition of $\mathrm{C}_{73} \mathrm{H}_{4.8} \mathrm{O}_{0.1}$, with the blend containing nearly $60 \%$ paraffins. The hydrogen selectivity was calculated to be $90 \%$. It should be noted that non-catalytic processes require temperatures in excess of $1000^{\circ} \mathrm{C}$ to achieve similar conversions, and at these high temperatures such high hydrogen selectivities are difficult to obtain.

The Argonne catalyst has demonstrated the ability to convert gasoline in the micro-reactor with high selectivity at relatively low temperatures. This catalyst will be further evaluated in the bench reactor to confirm its performance in a packed bed with non-uniform temperature and concentration profiles. Meanwhile, we are continuing to investigate new materials to obtain other catalysts that will provide similar or better conversions at still lower temperatures. Our future work plan also includes testing of the prototype reactor and development of start-up protocols to achieve rapidstart capability.

In the area of technology transfer, we have been working with engineers at General Motors Research and Development Center (Warren, MI) as they approach testing of the full-scale methanol partial oxidation reformer based on the Argonne design. Developments with these new hydrocarbon reforming catalysts are also being reported at various meetings. ${ }^{23}$ 


\section{REFERENCES}

1. R. Kumar, S. Ahmed, M. Krumpelt and

K. M. Myles, "Reformers for the Production of Hydrogen from Methanol and Alternative Fuels for Fuel Cell Powered Vehicles," ANL-92/31 (August 1992).

2. S. Ahmed, R. Kumar and M. Krumpelt, "Catalytic Partial Oxidation Reactor for Gasoline and other Fuels for Fuel Cell Automobiles," Windsor Workshop on Transportation Fuels, Windsor, Ontario, Canada, June 9-11, 1997.

3. Ahmed, R. Doshi, S. H. D. Lee, R. Kumar and M. Krumpelt, "Partial Oxidation Reformer Development for Fuel Cell Vehicles," $32^{\text {nd }}$ Intersociety Energy Conversion Engineering Conference, Honolulu, HI, July 27-August 1, 1997.

\section{B. Fuel Processing Research and Development - Preferential Oxidation Carbon Monoxide Control during On-Board Fuel Processing}

Michael Inbody, Nicholas Vanderborgh, José Tafoya, James Smith, James Hedstrom, Ken Stroh and Dennis Torraco

MS J-576, Fuel Cell Engineering Team, Los Alamos National Laboratory

Los Alamos, NM 87545

(505)-667-6651, fax: (505)-665-6173

\section{Objectives}

- Evaluate reformate cleanup operations to facilitate development of gasoline-fueled fuel cell systems.

- Design, fabricate, and evaluate a 50-kW preferential oxidatation (PROX) device to explore the chemical and thermal dynamics of preferential oxidation hardware for cleanup operations.

- Explore and evaluate alternate carbon monoxide reduction approaches.

- Evaluate effects of trace contaminants on PROX performance.

\section{Approach}

- Test catalysts and catalyst configurations to develop design and modeling data for the $50-\mathrm{kW}$ device, using a specially fabricated single-stage, full-size catalytic test reactor.

- Design, fabricate, and evaluate 20-kW PROX and integrate that hardware with the ADL Multifuel reformer; conduct integrated experiments.

- Design and fabricate a 50-kW PROX by integrating air injection/mixing sections and heat exchange sections with a staged catalyst configuration.

- Develop a unique short residence time experiment to measure catalyst kinetic data, measure effects of contaminants on catalyst performance, and investigate alternative $\mathrm{CO}$ reduction technologies.

- Develop modeling tools to assist in design using process models, detailed reactor models, and CFD models.

- Collaborate with industrial leaders to assure timely addressing of significant technical issues. 


\section{Accomplishments}

- Designed, fabricated, and tested a 20-kW PROX device and successfully integrated that device with the Arthur D. Little, Inc. (ADL) multifuel fuel processor to demonstrate the first production from gasoline of a Proton Exchange Membrane (PEM) fuel cell quality anode feed.

- Designed and fabricated, based on results from the integrated experiment, a single-stage catalytic test reactor to facilitate design of the next generation of hardware.

- Gathered performance data on a variety of catalyst types, reactor designs, and control strategies using simulated gasoline reformate to facilitate the 50-kW PROX engineering.

- Designed, as a sub-assembly, a 20-kW PROX specifically to conduct the first gasoline-to-electricity experiment (October 1997).

- Developed a stand-alone control system, based on laboratory data acquisition and control experience, to address control and safety issues during experiments away from Los Alamos National Laboratory (LANL).

- Designed a short residence time reactor to facilitate rapid evaluation of alternative control approaches required for reformate cleanup.

\section{Future Directions}

- Determine transient performance and develop acceptable control techniques that maintain gas quality through transient events.

- Demonstrate the LANL 50-kW PROX as an integrated unit with multifuel fuel processing hardware.

- Evaluate control techniques on the up-stream side of the PROX to assure that contaminants are maintained at levels that can be successfully controlled.

- Evaluate alternative options for contaminant control that augment or supplement the PROX design.

- Investigate techniques for effective control of other contaminants such as $\mathrm{NH}_{3}, \mathrm{H}_{2} \mathrm{~S}$ and other constituents in conjunction with the PROX cleanup of $\mathrm{CO}$.

\section{Introduction/Objectives}

On-board fuel processing of fuels gasoline, methanol, ethanol, and natural gas, to generate hydrogen-rich gas for a PEM fuel cell stack anode feed requires cleanup to achieve gas purity levels. Anode cleanup technology should operate well through a wide range of hydrogen concentrations, should operate in a contaminant tolerant manner, should be transient capable, should afford controlled stable operation, and should operate efficiently with minimal hydrogen consumption. To be viable for automotive applications, the multifuel gas cleanup device must meet volume and cost targets. The objective of this work is to develop such cleanup technology.

The LANL approach has been to extend and refine PROX technology, originally developed for $\mathrm{CO}$ removal from methanol reformate, to $\mathrm{CO}$ and other contaminant removal from a range of reformate gas mixtures. The primary FY97 objective has been to develop the PROX technology for application to gasoline fuel processing at a $50-\mathrm{kW}$ fuel cell power system scale.

Three of our main tasks are summarized in the following paragraphs.

\section{Definitive Experiment of Integrated PROX-Gasoline Reformer Hardware}

We developed a unique PROX device for integration with the Multifuel Reformer hardware at Arthur D. Little Inc. in Cambridge, MA. This LANL PROX was designed for simulated gasoline reformate at a maximum flow sufficient to produce $20 \mathrm{~kW}_{\mathrm{e}}$ from a modern PEM stack. 
This PROX was a two-stage design, with two, parallel first-stage catalytic beds flowing into a single second-stage catalytic bed. A customized water heat-pipe component provided inter-stage cooling of the gases, removing the majority of the heat produced during the oxidation steps. At low flows, only one of the first stage beds was used, and at higher flows both participated in the control. This way the residence time in the PROX was maintained reasonably constant to meet transient response and turndown ratio specifications. The hardware design utilized weld flanges for quick change of the catalyst and for reconfiguration of the PROX reactor, while providing appropriate safety for these hydrogen experiments.

Calibration PROX experiments were first conducted at LANL using simulated gasoline reformate, nominally a gas mixture containing $36 \%$ $\mathrm{H}_{2}, 29 \% \mathrm{~N}_{2}, 17 \% \mathrm{CO}_{2}$, and $17 \% \mathrm{H}_{2} \mathrm{O}$, with $\mathrm{CO}$ concentration in the range from $1,000 \mathrm{ppm}$ to $10,000 \mathrm{ppm}$. Oxygen is added to this mixture, metered as a function of the $\mathrm{CO}$ concentration. Oxygen stoichiometry is defined as the ratio of the moles of oxygen injected to that amount required to completely combust the moles of $\mathrm{CO}$ in the reaction, $\mathrm{CO}+1 / 2 \mathrm{O}_{2}=\mathrm{CO}_{2}$. These LANL experiments showed that the first stage of the PROX reduces the $C O$ concentration from $8000 \mathrm{ppm}$ to below $1000 \mathrm{ppm}$ through a wide range in oxygen stoichiometry equivalent to an $18 \%$ variation in air flow rate (Fig. 1).

(We were concerned about the necessity for precise air metering in this "automotive hardware." These results show simple air metering is sufficient.) As shown in Figure 2, the second stage

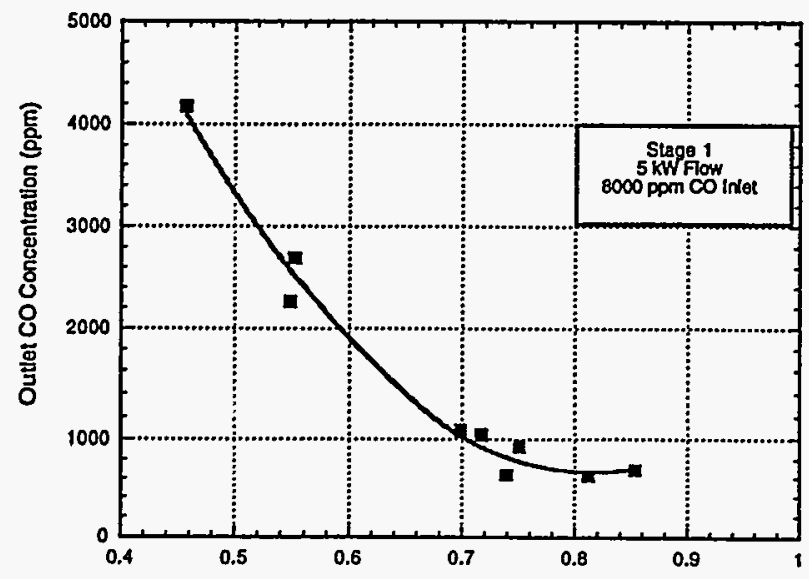

Figure 1. Outlet $\mathrm{CO}$ concentration of the PROX first stage as a function of oxygen stoichiometry.

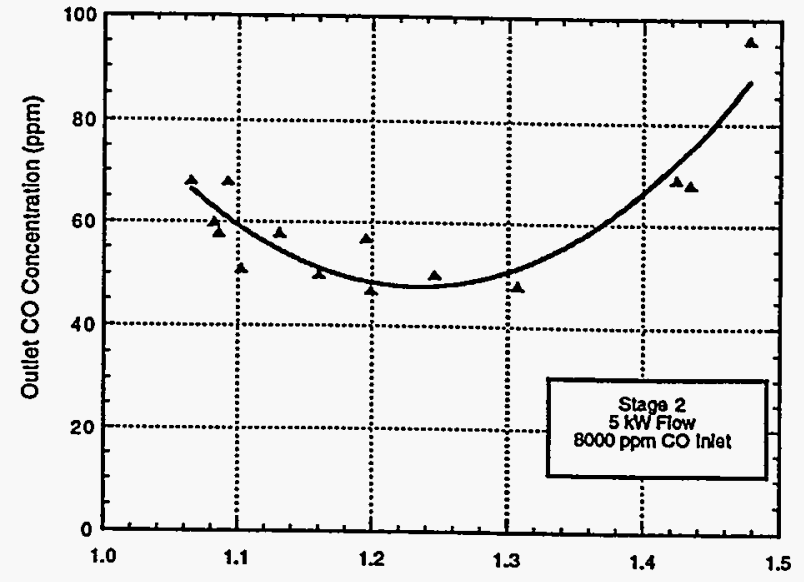

Figure 2. Outlet $\mathrm{CO}$ concentration of the PROX second stage as a function of the overall oxygen stoichiometry (first and second stage air injection combined).

reduces the outlet $\mathrm{CO}$ concentration below $50 \mathrm{ppm}$ $C O$ over a range equivalent to a $50 \%$ variation in the stage 2 air injection. Thus, $\mathrm{CO}$ specifications below $50 \mathrm{ppm}$ can be achieved, with about a $20 \%$ excess oxygen concentration.

Figure 3 shows the response of the PROX outlet $\mathrm{CO}$ concentration to a variation in the inlet $\mathrm{CO}$ concentration from $4000 \mathrm{ppm}$ to $8000 \mathrm{ppm}$ of $\mathrm{CO}$ at constant flow and operating conditions. The outlet $\mathrm{CO}$ concentration remains below $60 \mathrm{ppm}$ over the range and improves to about $30 \mathrm{ppm}$ as the inlet

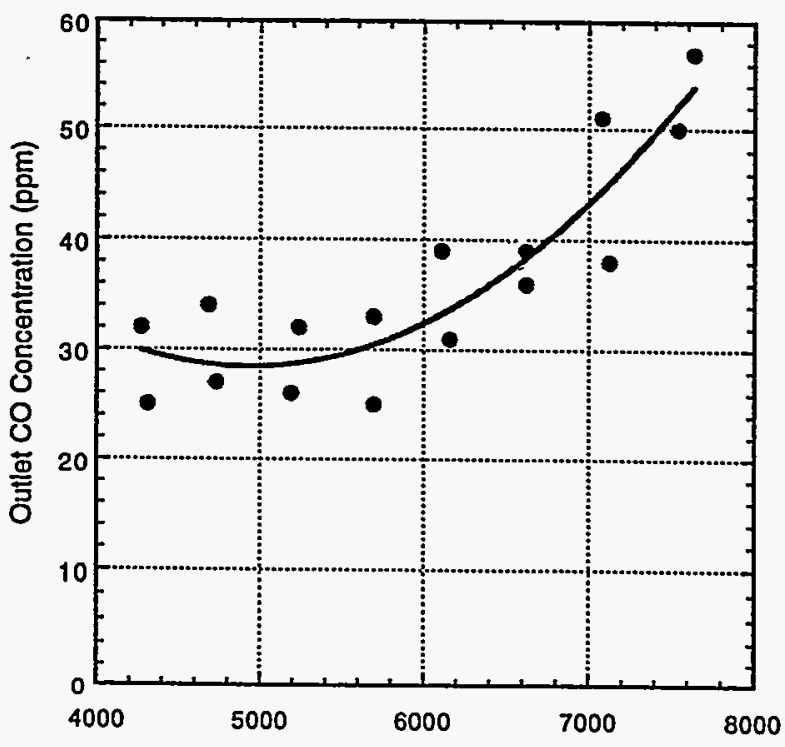

Figure 3. PROX outlet $\mathrm{CO}$ concentration as a function of the inlet $\mathrm{CO}$ concentration at flow and operating conditions for $5-\mathrm{kW}$ equivalent. 
$\mathrm{CO}$ concentration is reduced. These results are presented to illustrate LANL calibration studies.

Following the testing at LANL with synthetic reformate, the PROX was shipped to ADL in Cambridge, MA, and integrated with the multifuel reformer. The PROX, attached to the reformer output, was operated manually. Testing was done during a two day period, with the reformer operating on gasoline. The PROX device generated product gas with $\mathrm{CO}$ levels sufficiently low for successful PEM stack operation.

\section{Single-Stage Catalytic Test Reactor}

Based on integrated test results, we designed and built a single-stage catalytic test reactor (SSCTR) to address uniformly mixed gas mixtures and uniform flows and temperature distributions across the catalyst bed entrance volume. Because of difficulties with scaling the fluid dynamics predictions, we built this experiment at full scale. This SSCTR was used for three sets of experiments: 1) validation of the performance of rebuilt LANL PROX catalytic reactor stages; 2) measurement of temperature and gas concentration profiles in a catalytic reactor test section; and 3) measurement of design data for scaling reactors to operate at the $50-\mathrm{kW}$ equivalent scale. Our gas chromatography methods were improved to be faster and to include measurements of methane and oxygen along with carbon monoxide.

Figures 4 through 6 show gas concentrations of carbon monoxide, oxygen, and methane as a function of bed length in a catalytic volume with a $5-\mathrm{kW}$ equivalent flow of gasoline reformate with $6000 \mathrm{ppm} \mathrm{CO}$ at an inlet temperature of $140^{\circ} \mathrm{C}$.

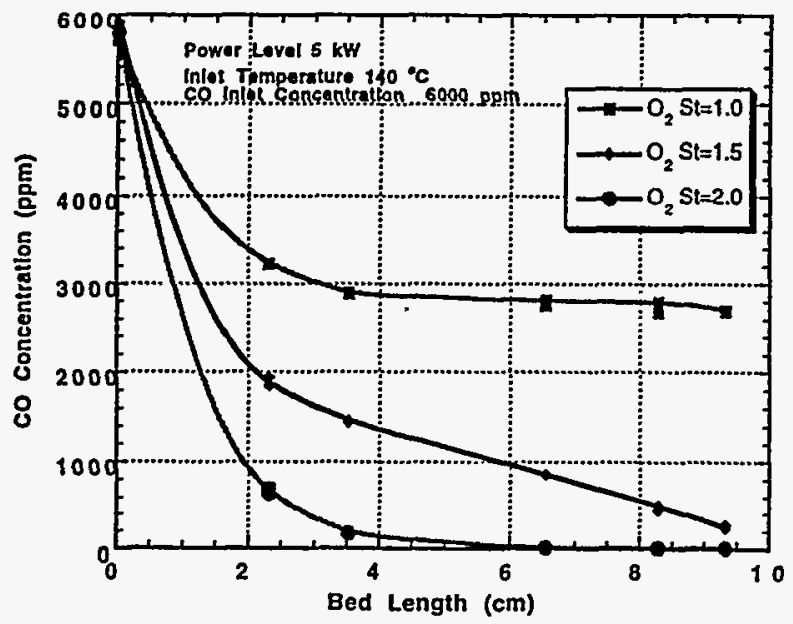

Figure 4. $\mathrm{CO}$ concentration measured as a function of bed length at three oxygen stoichiometries.

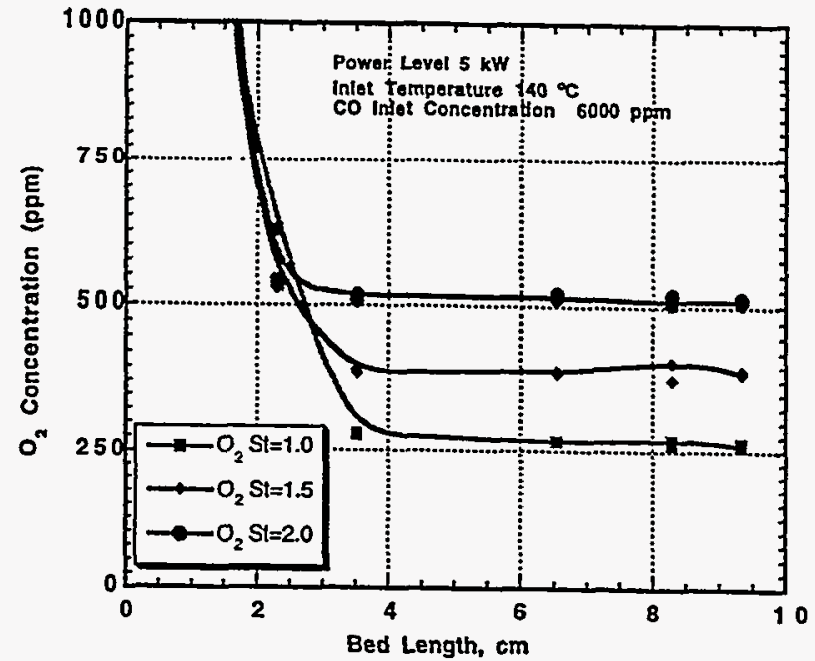

Figure 5. Oxygen concentration measured as a function of bed length at three oxygen stoichiometries.

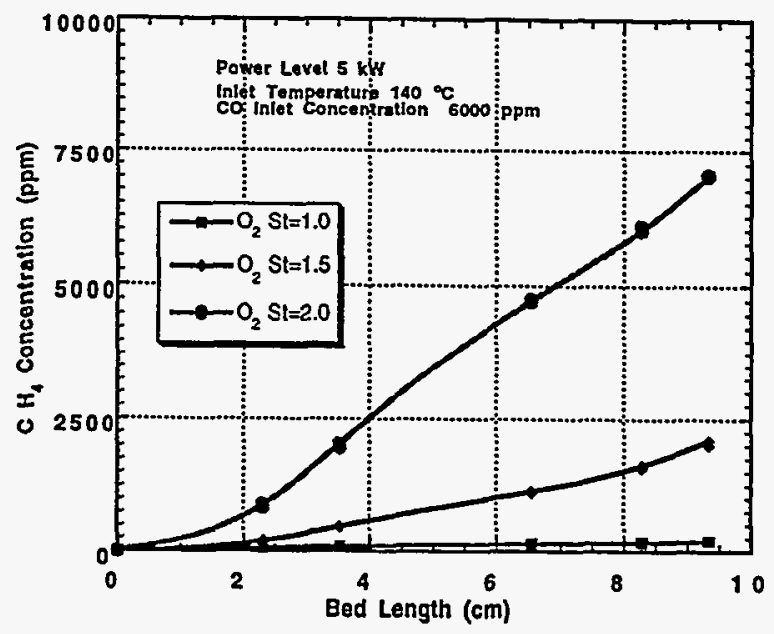

Figure 6. Methane concentration measured as a function of bed length for three oxygen stoichiometries.

Figure 7 shows the temperature profiles measured at the same conditions. Profiles were measured at three $\mathrm{O}_{2}$ stoichiometries, 1.0,1.5, and 2.0. These profiles give us an understanding of the $\mathrm{CO}$ removal process in these catalytic devices.

Figure 4 shows that the $\mathrm{CO}$ concentration decreases rapidly within the first $3 \mathrm{~cm}$ of the catalyst bed and more slowly through the rest of the traverse, as expected by modeling results. This rapid decline of $\mathrm{CO}$ concentration is accompanied by $\mathrm{O}_{2}$ depletion at the inlet side, shown in Figure 5. These data actually show $\left[\mathrm{O}_{2}+\mathrm{Ar}\right]$, so the oxygen is essentially depleted quickly in the first few $\mathrm{cm}$. Figure 6 shows that the methane concentration increases toward the end of the device, 


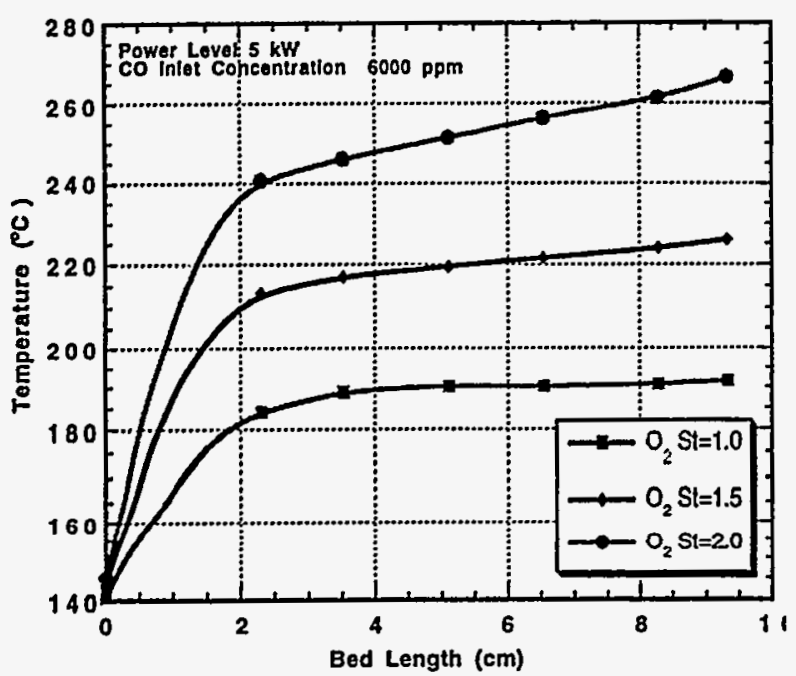

Figure 7. Temperature measured as a function of bed length for three oxygen stoichiometries.

more so at higher $\mathrm{O}_{2}$ stoichiometries, such that more oxygen results in higher temperatures.

These data suggest that methanation is the route for continued $\mathrm{CO}$ removal once oxygen is depleted. At an $\mathrm{O}_{2}$ stoichiometry of 2 , the $\mathrm{CO}$ concentration falls below $500 \mathrm{ppm}$ after $3 \mathrm{~cm}$, while the $\mathrm{CH}_{4}$ concentration increases from about $2000 \mathrm{ppm}$ to about $7000 \mathrm{ppm}$ at the exit. This result implies methanation of $\mathrm{CO}_{2}$. The temperature profiles in Figure 7 show a rapid rise in temperature in the first $3 \mathrm{~cm}$ corresponding to the consumption of $\mathrm{O}_{2}$ in the oxidation reactions of $\mathrm{CO}$ and $\mathrm{H}_{2}$. The temperature rise beyond $3 \mathrm{~cm}$ at oxygen stoichiometries of 1.5 and 2.0 correspond to the heat generated by the methanation reactions. Comparison of the temperature profiles (Fig. 7) with the methane profiles (Fig. 6) shows the temperature must be maintained below $225^{\circ} \mathrm{C}$ to restrict $\mathrm{CH}_{4}$ formation.

\section{0-kW PROX Design and Fabrication}

The LANL PROX design approach combines primary preferential oxidation of $\mathrm{CO}$ supplemented with methanation to achieve a high degree of process control. We show successful preferential oxidation for removal of $\mathrm{CO}$, but that process must be conducted with precise air injection, inlet temperature, or catalyst residence time to retard the self-defeating reverse-shift formation of $\mathrm{CO}$. Methanation is also successful for $\mathrm{CO}$ removal, but consumes excessive amounts of $\mathrm{H}_{2}$, and, in the event of a thermal runaway, methanates $\mathrm{CO}_{2}$. Consequently, the LANL approach combines preferential oxidation with methanation to address the initial large $\mathrm{CO}$ removal with oxidation and then completes the polishing with methanation.
Under some designs, this can be accomplished in a single catalyst volume. Using this new approach, a prototype catalytic reactor was tested over a range of simulated gasoline reformate flows corresponding to fuel cell equivalent flows from $7.5 \mathrm{~kW}$ to $20 \mathrm{~kW}$.

A 50-kW PROX and a 20-kW PROX were designed and fabricated. The fuel cell equivalent power specifications for these PROXs are based on the $\mathrm{H}_{2}$ requirements for a fuel cell stack operating at an anode stoichiometry of $1.25(80 \% \mathrm{H}$ utilization) with an average cell voltage of $0.6 \mathrm{~V}$. Total flow specifications were based on the composition of simulated gasoline reformate used in our prior experiments. The 50-kW PROX uses a three-stage, highly compact design to handle a wide range of flow rates and inlet $C O$ concentrations and yet maintain low outlet $C O$ concentrations and mini$\mathrm{mal}_{2}$ consumption through transients. Air injection/mixing, flow distribution, and inter-stage heat exchange are incorporated in each stage in a compact manner.

The 20-kW PROX uses similar design concepts but with a shorter cross-section and a two-stage design set for a more narrow range of flow rates. The 20-kW PROX was specifically built for a demonstration for the next integrated gasoline reformer experiment, which will include stack operation (October, 1997). 


\section{CO Removal from Reformate}

Romesh Kumar, Sheldon Lee, Kurt Kramarz, J. David Carter and Michael Krumpelt

Argonne National Laboratory, Argonne, IL 60439-4837

(630) 252-4342, fax: (630) 252-4176

\section{Objectives}

- Explore alternative techniques to reduce $\mathrm{CO}$ in reformate to levels less than $100 \mathrm{ppm}$ in an easily controllable dynamic manner.

- Develop CO clean-up techniques that can operate at ambient temperatures as well as at fuel cell temperatures.

\section{Approach}

- Remove CO from the reformate by complexing it with acidic cuprous chloride.

- Preferentially oxidize the $\mathrm{CO}$ using a ceramic membrane device, where the oxygen injection rate is dynamically controlled by electrochemical means.

\section{Accomplishments}

- Preliminary tests showed that $\mathrm{CO}$ in the concentration range of $1-30 \%$ by volume can be removed by $\mathrm{CuCl}$ in solution or as a solid sorbent; the complex can be easily regenerated.

- For the ceramic CO clean-up device, early performance was too low by a factor of eight, but the steps needed to achieve the desired performance were identified.

\section{Future Directions}

- Determine thermodynamic limitations for the $\mathrm{CuCl}-\mathrm{CO}$ complexing approach to establish the operating conditions of temperature, pressure, etc.

- Develop effective techniques for dispersing $\mathrm{CuCl}$ on high surface area substrates to increase sorbent utilization and the $\mathrm{CO}$ sorption/desorption rates.

- Improve performance for the ceramic CO clean-up device and test laboratory-scale cells with $\mathrm{CO} / \mathrm{H} 2$ gases for preferential $\mathrm{CO}$ oxidation and the effect of temperature on $\mathrm{CO}$ selectivity.

Polymer electrolyte fuel cells operate by electrochemically oxidizing hydrogen to generate electricity. Any on-board fuels other than hydrogen must first be converted to hydrogen. This reforming process also generates carbon monoxide, which is a strong poison for the anode catalyst and severely degrades fuel cell performance. The bulk of the carbon monoxide in the reformate can be converted to carbon dioxide and additional hydrogen by the water-gas shift reaction. The residual $0.5-1 \% \mathrm{CO}$, however, must be reduced to $100 \mathrm{ppm}$ or less by other means. Catalytic preferential oxidation, anode air bleed, or a combination of the two can be used to restore fuel cell performance, but their use in a dynamically varying system is problematic.

We are investigating two alternative approaches for the removal of $\mathrm{CO}$ from reformate. The first is to use acidic cuprous chloride (or other suitable sorbent) to chemically bind and thus remove the $\mathrm{CO}$ from the reformate; this sorbent would then be regenerated in a cyclic fashion. It may also be possible, depending upon the sorbent and the 
sorption chemistry, to devise a continuous process using this approach. An additional major advantage of the chemical scrubbing technique for removing $\mathrm{CO}$ is that it will operate at room temperature (as well as higher temperatures), thus yielding essentially instantaneous start-up of the device.

The second approach is to use an Atunable@ oxygen-conducting ceramic membrane to provide the precise, dynamically varying amount of oxygen needed for the preferential oxidation of $\mathrm{CO}$ (without the accompanying nitrogen, as is the case with air injection), directly to the catalyst's active sites.

\section{CO Removal by Complexing with $\mathrm{CuCl}$}

This concept is based on the reversible complex formation and dissociation reactions between $\mathrm{CO}$ and $\mathrm{CuCl}$. Such a complex may take several forms:

$$
\begin{gathered}
\mathrm{CO}+\mathrm{CuCl}(\mathrm{s}) \int \mathrm{Cu}(\mathrm{CO}) \mathrm{Cl}(\mathrm{s}) \\
\mathrm{CO}+\mathrm{CuCl}(\mathrm{aq} \mathrm{HCl} \text { or } \mathrm{KCl}) \int \mathrm{Cu}(\mathrm{CO}) \mathrm{Cl} 9 \\
2 \mathrm{CO}+2 \mathrm{H} 2 \mathrm{O}+2 \mathrm{CuCl} \int(\mathrm{Cu}(\mathrm{CO}) \mathrm{ClH} 2 \mathrm{O}) 2 \\
\mathrm{CO}+\mathrm{CuCl}+3 \times \int[\mathrm{Cu} 3 \mathrm{CO}]+\mathrm{Cl}^{-}
\end{gathered}
$$

where $X$ is $\mathrm{NH} 4 \mathrm{Cl}$ or aqueous $\mathrm{NH}_{3}$. Other complexes are also possible, depending on the substrate used.

We have conducted two types of experiments to prove the concept. In one, the $\mathrm{CuCl}$ was dissolved in an aqueous solution of $\mathrm{HCl}$ or $\mathrm{KCl}$; the solution was then used to scrub $\mathrm{CO}$ out of a gas mixture with $\mathrm{H}_{2}$ and $\mathrm{N}_{2}$. In the other, solid $\mathrm{CuCl}$ was dispersed on a substrate, and the uptake of $\mathrm{CO}$ was measured using a thermogravimetric analyzer (TGA) to monitor weight change in the sorbent as it was exposed to gases containing varying concentrations of $\mathrm{CO}$ in $\mathrm{N}_{2}$.

The solution tests were conducted at $1 \mathrm{~atm}$ and 25EC, using a solution of $3.5 \mathrm{~g}$ of $\mathrm{CuCl}$ dissolved in $320 \mathrm{ml}$ of $2 \mathrm{M} \mathrm{HCl}$ or $\mathrm{KCl}$. Figure 1 shows the concentration of $\mathrm{CO}$ as a function of time ( $\mathrm{min}$ ). The horizontal line at $0.96 \% \mathrm{CO}$ is the concentration of $\mathrm{CO}$ in the inlet test gas. The data points show the concentration of $\mathrm{CO}$ in the gas leaving the scrubber. The solid triangles show that with water alone, there was little absorption of $\mathrm{CO}$ and the exit concentration of $\mathrm{CO}$ reached the inlet concentration fairly rapidly. With either of the $\mathrm{CuCl}$ solutions, on the other hand, it took several minutes for the $\mathrm{CO}$ concentration in the exit gas to approach that in the inlet gas, indicating that the $\mathrm{CuCl}$ solutions were able to remove $\mathrm{CO}$. However, the amount of CO removed was only about $12 \%$ of the total $\mathrm{CO}$ in the feed gas, and the effectiveness of $\mathrm{CuCl}$ utilization was less than $2 \%$.

For tests with the solid sorbent, the $\mathrm{CuCl}$ was supported on a high surface area substrate. The TGA tests were conducted with gas mixtures containing $3-30 \% \mathrm{CO}$ in N2. Figure 2 shows photomicrographs of the fresh substrate and the substrate containing $\mathrm{CuCl}$.

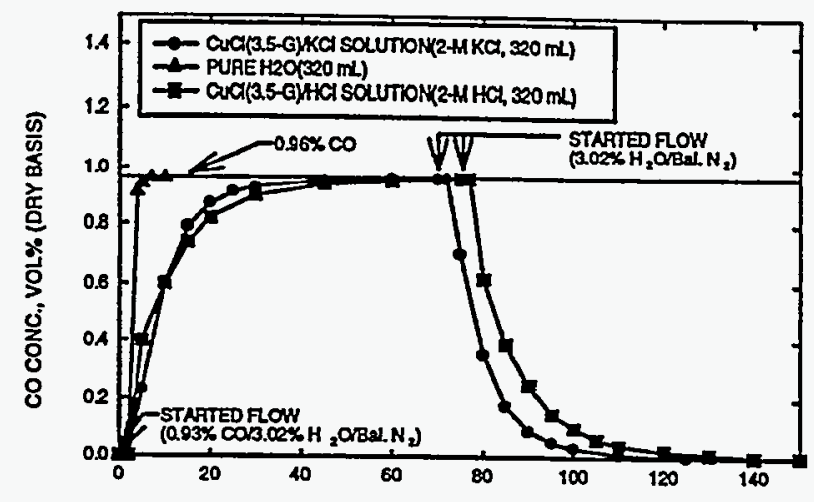

Figure 1. Sorption/desorption of $\mathrm{CO}$ in water and in $\mathrm{CuCl} / \mathrm{KCl}$ and $\mathrm{CuCl} / \mathrm{HCl}$ solutions.
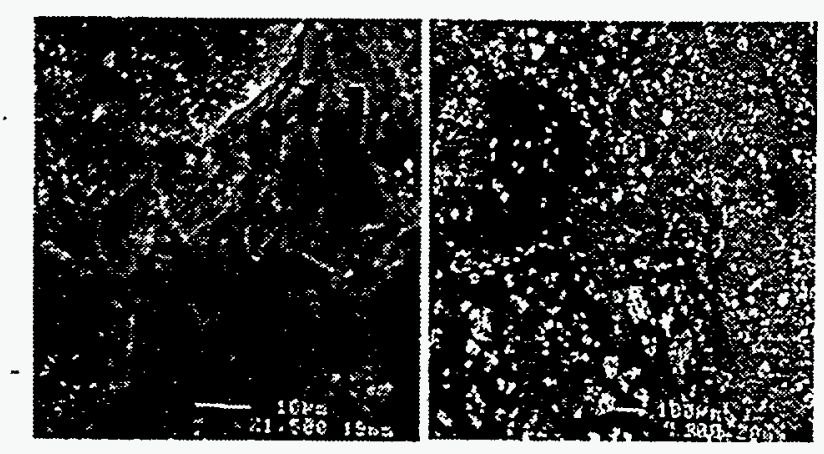

Figure 2. Fresh substrate (left) and substrate with $\mathrm{CuCl}$ (right).

Results of $\mathrm{CO}$ sorption and desorption with this sorbent are shown in Fig. 3. The sorption of $\mathrm{CO}$ from the gas mixture was rapid and reproducible. The amount of $\mathrm{CO}$ adsorbed decreased with lower concentrations of $\mathrm{CO}$ in the gas, but the decrease was not linearly proportional to the $\mathrm{CO}$ concentration.

Thus, results of tests of the concept to use $\mathrm{CuCl}$ to remove $\mathrm{CO}$ from reformate indicate that it is possible to do so with either the solution or the solid sorbent approach. The captured $\mathrm{CO}$ is easily released from the complex with $\mathrm{CuCl}$, and the rates of sorption and desorption are relatively rapid. 


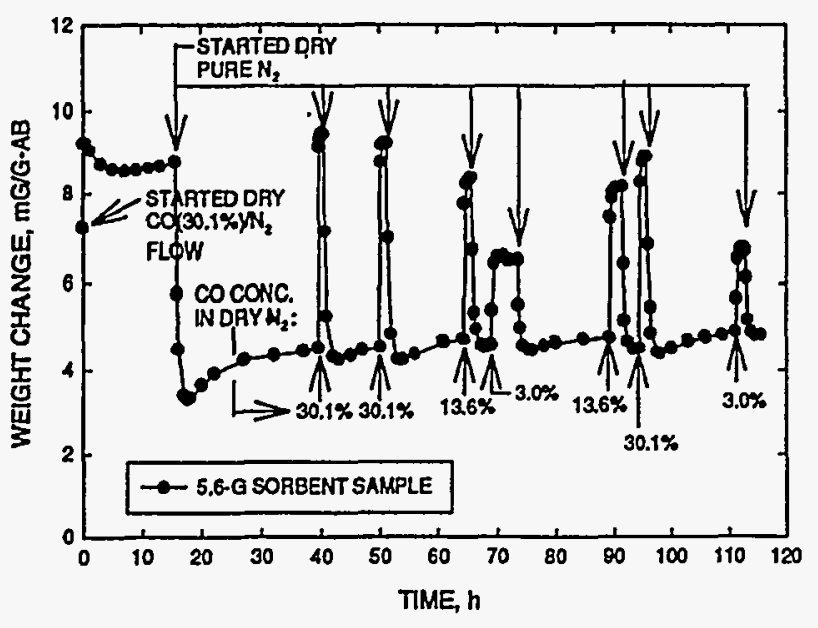

Figure 3. Results of $\mathrm{CO}$ sorption/desorption tests on solid $\mathrm{CuCl}$.

In future work we will determine the thermodynamic limitations for the complexing of $\mathrm{CO}$ with $\mathrm{CuCl}$ as a function of temperature, pressure, $\mathrm{CO}$ concentration, and the reformate composition. We will develop dispersion techniques for the promising sorbents on high surface area substrates to increase CO sorption/desorption rates as well as to increase sorbent utilization. We will also investigate other potential chemical sorbents. Finally, we need to test this process with actual reformate from gasoline or methanol reforming.

\section{CO Removal Using Ceramic Membrane Device}

The second technique for $\mathrm{CO}$ removal uses an electrochemical ceramic device to achieve $\mathrm{CO}$ oxidation. In this approach, the $\mathrm{O}_{2}$ is supplied directly to the preferential oxidation catalyst. The process is easy to control and offers quick response to changes in the flow rate of the fuel gas.
Based on preliminary tests, for a 50-kW fuel cell system, an oxygen current equivalent to $70 \mathrm{~A}$ is needed. With a projected cell performance of $1 \mathrm{~S}-\mathrm{cm}^{2}$ at $500 \mathrm{EC}$ (corresponding to $50 \mathrm{~S}-\mathrm{cm}^{2}$ at $300 \mathrm{EC}$ ), the required ceramic membrane area is $\sim 3500 \mathrm{~cm}^{2}$ at $300 \mathrm{EC}$, and less at higher operating temperatures.

We are presently working with gadoliniumdoped cerium oxide as the oxygen-conducting ceramic. This material can provide the desired oxygen flux if the ceramic membrane thickness can be reduced to $50 \mathrm{~m}$ or less.

Future work to develop this technique further will involve fabrication of a thin-layer ceramic electrolyte and improvement in the activity of the cathode and anode (i.e., reduction of the electrode polarizations). Also, complete cells will be tested in $\mathrm{CO} / \mathrm{H}_{2} / \mathrm{N}_{2} / \mathrm{H}_{2} \mathrm{O}$ atmospheres to verify the preferential oxidation of $\mathrm{CO}$ and to determine the effect of temperature on CO-to- $\mathrm{H}_{2}$ oxidation selectivity.

\section{PUBLICATIONS}

Youchang Xie, et al., "Adsorbents for Use in the Separation of Carbon Monoxide and/or Unsaturated Hydrocarbons from Mixed Gases," U. S. Patent No. 4,917,711 (April 17, 1990).

$X . D$. Peng, et al., "CO Adsorbents Based on the Formation of a Supported $\mathrm{Cu}(\mathrm{CO}) \mathrm{Cl}$ Complex," Langmuir, Vol. 11, No. 2, pp. 534-537 (1995). 


\section{Microchannel Fuel Processor Components}

Robert S. Wegeng and Anna Lee Y. Tonkovich

Pacific Northwest National Laboratory, P.O. Box 999,

Richland, WA 99352

(509)373-9015, fax: (509)536-1867

\section{Objectives}

- Demonstrate very compact reactors and heat exchangers based on microsystems technology for the onboard, automotive production of hydrogen from liquid hydrocarbons.

\section{Approach}

- Fabricate and test integrated microchannel heat exchangers and reactors with very high heat and mass transport rates, very low residence times, and very high production rates per unit hardware volume.

\section{Accomplishments}

- Demonstrated a "bench-scale" fuel vaporizer that consists of reactor and heat exchanger cells for the vaporization of the fuel stream prior to chemical processing. The unit recovers energy from the hydrogen remaining in the offgas of the fuel cell anode prior to discharge to the atmosphere.

- Demonstrated a "full-scale" fuel vaporizer that incorporates four parallel processing reactor and heat exchanger cells and occupies $1^{\prime \prime} \times 3^{\prime \prime} \times 4^{\prime \prime}$ in volume. Two of these units would be required for the vaporization of the entire fuel stream for a $50-\mathrm{kWe}$ fuel cell system.

\section{Future Directions}

- Continue operational testing of bench-scale and full-scale vaporizers. The primary goal is to improve the flow uniformity between cells to a less than $2 \%$ deviation.

- Develop and demonstrate other microtechnology-based, fuel processor components, including partial oxidation, water-gas-shift and preferential oxidation reactors.

- Develop embedded controls elements, allowing reactor systems to regenerate individual cells while the remainder of the system is still online.

- Demonstrate a complete, microtechnology-based fuel processor system.

The development of an onboard fuel processing system to produce hydrogen gas from liquid hydrocarbons for fuel cell use presents a number of technical challenges, including process miniaturization and thermal energy integration. The approach utilized by this project consists of developing integrated reactors and heat exchangers using microfabrication techniques that have the potential of realizing very compact systems with high throughputs and thermal efficiencies.
An extremely compact fuel vaporizer ( 1 " $\times 3^{\prime \prime} \times$ 4") for automotive fuel cell/fuel processing systems has been demonstrated (Fig. 1). This vaporizer consists of four reactor cells and four heat exchanger cells, is fabricated using micromachining techniques, and exploits the extremely rapid heat and mass transport rates that are possible in engineered microstructures. The system is able to vaporize $400 \mathrm{~mL} / \mathrm{min}$ of methanol; two units operating in parallel can provide 


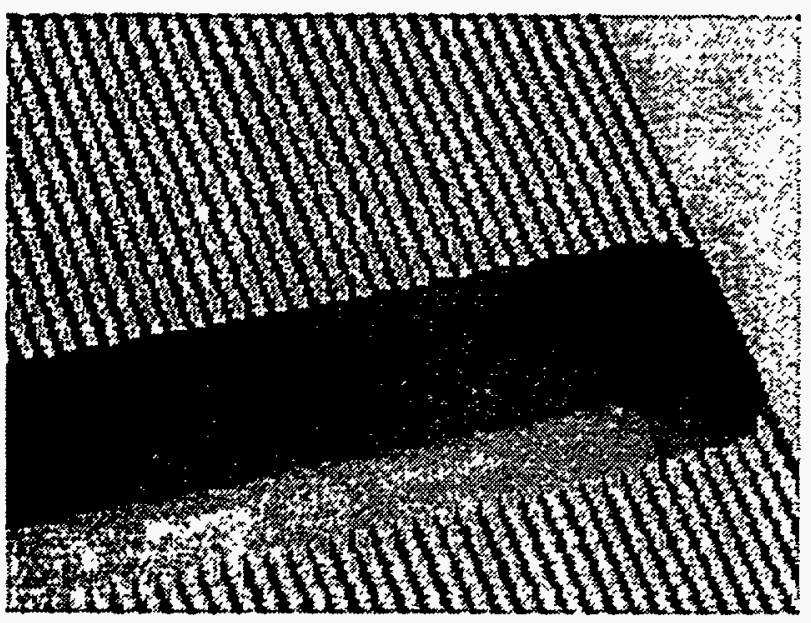

Figure 1. Compact fuel vaporizer.

sufficient vapor fuel stream for a 50-kWe automotive system. The disassembled, full-scale system is shown in Figure 2.

As shown in the accompanying process diagram (Fig. 3), the fuel vaporizer captures and recycles energy from unused hydrogen in the fuel cell waste gas by catalytically reacting it with air, and then routing the stream through microchannel heat exchangers within which methanol is evaporated. The microchannels (Fig. 1) are typically 150-300 microns wide and one to several millimeters deep, supporting heat fluxes exceeding $150 \mathrm{~W} / \mathrm{cm} 2$. The aspect ratio for the gas-side heat transfer is 18:1, while the aspect ratio on the vaporizing side is much lower (7:1).

The combustion catalyst is palladium, which has the distinct advantage of lighting-off at room temperature. Sub-ambient temperatures, which

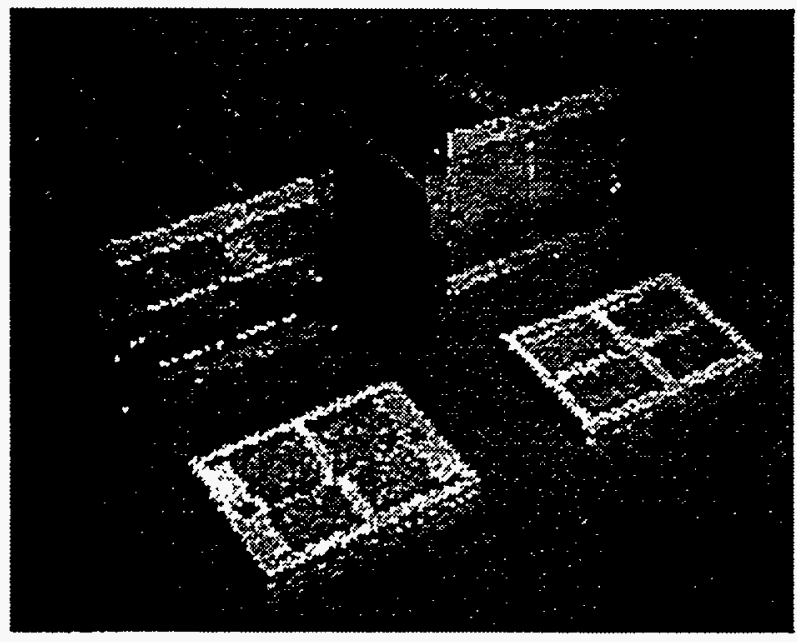

Figure 2. Disassembled, full-scale compact fuel vaporizer.

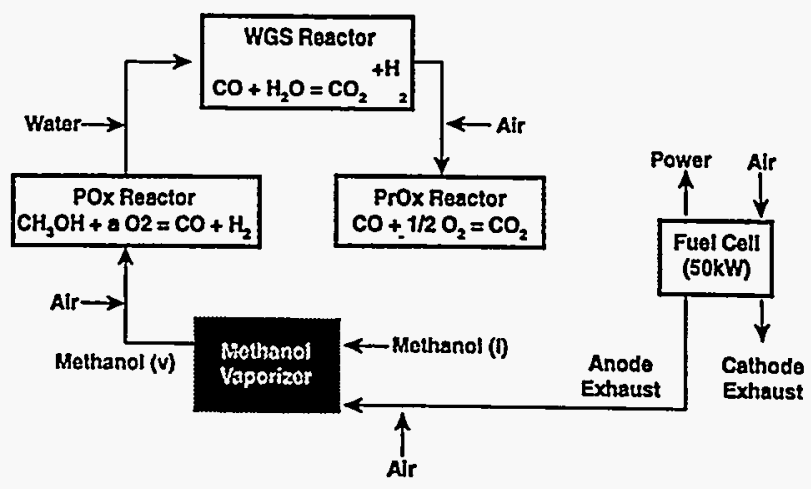

Figure 3. Fuel vaporizer process diagram.

mimic a cold-start in the winter, have not yet been evaluated.

Early bench-scale prototypes had system efficiencies near $70 \%$ and incomplete hydrogen conversion. In the latter stages of the prototype development, complete hydrogen combustion occurred because improvements were made in the catalyst formulation and its deployment as an engineered microstructure. The overall system efficiency increased to $90 \%$ with advances in the design of the microchannels. A near linear relationship between system efficiency and the gas-side aspect ratio was observed in the bench-scale unit.

The results of the bench-scale experimentation were used for designing a full-scale system, consisting of four parallel processing reactor and heat exchanger cells. Subsequent experimental efforts confirmed that two of these units, each occupying a $1^{\prime \prime} \times 3^{\prime \prime} \times 4^{\prime \prime}$ volume, would be required for the vaporization of the entire fuel stream for a $50-\mathrm{kWe}$ fuel cell system. For the full-scale unit, the overall system efficiency was determined to be $89 \%$ with complete hydrogen conversion. Design revisions were made to improve the methanol flow uniformity through multiple cells.

The results of this fuel vaporizer project for the Department of Energy show that catalytic microchannel reactors and heat exchangers can be fabricated and operated in parallel to realize an extremely compact, lightweight system that produces product streams that are appropriate in volume for automotive applications. Follow-on steps include:

- Vaporizer testing over extended durations.

- Development and demonstration of other compact, automotive fuel processing reactors (e.g., partial oxidation, water-gasshift, and preferential oxidation reactors), using engineered microstructures. 
- Testing with embedded controls, enabling partial load operation while maintaining optimal reaction/heat transfer conditions in individual cells.

- Demonstration of an integrated, microtechnology-based fuel processing system in an automobile.

\section{PUBLICATIONS}

Tonkovich, A., C. Call, D. Jimenez, R. Wegeng and M. Drost, "Microchannel Heat Exchangers for Chemical Reactors" Heat Transfer - Houston 1996 (AICHE Symposium Series 310) , 119-125 (1996).

Tonkovich, A.Y., J. L. Zilka, D. M. Jimenez, M. J. Lamont and R.S. Wegeng, "Microchannel Chemical Reactors for Fuel Processing," accepted for publication and presentation, AICHE Conference on Process Miniaturization, March 1998.

Wegeng, R.S. and M. K. Drost, "Developing New Miniature Energy Systems," Mechanical Engineering, 116, 82-85 (1994).
Wegeng, RS. , C. J. Call and M. K Drost, "Chemical System Miniaturization," PNNL SA-27317, AICHE 1996 Spring National Meeting, Invited Paper \#107a, New Orleans, Louisiana, February 1996. Also available on the world wide web at http://www.pnl.gov/edo/programs/ fliers/microfly.htm

Wegeng, R.S., J. G. Birmingham, C. J. Call, M. K. Drost, M. Friedrich, D. E. Kurath, P. M. Martin, W. D. TeGrotenhui and A.Y. Tonkovich, "Micro Chemical System Development Progress at the Pacific Northwest National Laboratory," DECHEMA Ist International Conference on Microreaction Technology, Frankfurt, Germany, February 1997.

Wegeng, R.S., “Opportunities for Distributed Processing using Micro Chemical Systems," accepted for publication and presentation, AICHE Conference on Process Miniaturization, March 1998. 


\title{
IV. PEM FUEL CELL MODELING, TEST AND EVALUATION
}

\author{
A. Modeling of Automotive Fuel Cell Systems
}

Romesh Kumar, Rajesh Ahluwalia, Ezzat Doss and Howard Geyer

Argonne National Laboratory, Argonne, IL 60439-4837

(630) 252-4342, fax: (630) 252-4176

\section{Objectives}

Develop computer models of polymer electrolyte fuel cell (PEFC) systems for the automotive application to

- determine key design parameters and operating efficiencies;

- evaluate start-up and dynamic performance of the fuel cell system and its components; and

- provide information to the Fuel Cell, Systems Analysis, and Vehicle Engineering Teams of the Partnership for a New Generation of Vehicles (PNGV), as needed.

\section{Approach}

Develop a system design and analysis code that

- consists of component models (as $C$ data structures), mathematical utilities, property utilities, and thermodynamic data;

- permits variable system configurations (including recycle loops) and system constraints; and

- performs parameter sweeps, optimizations, and time integrations (for dynamic simulations).

\section{Accomplishments}

Working with the PNGV Fuel Cell, Systems Analysis, and Vehicle Engineering Technical Teams,

- determined design-point and part-load performance of hydrogen- and gasoline-fueled fuel cell systems;

- determined component weights, volumes, flow rates, etc., for a vehicle packaging study; and

- determined start-up and dynamic performance of hydrogen-fueled systems on specific driving schedules.

\section{Future Directions}

- Develop dynamic model of gasoline partial-oxidation reformer and the preferential oxidation (PROX) unit.

- Determine start-up, steady-state, and dynamic performance of gasoline-fueled systems.

- Validate component and system models as data become available. 
We have developed a computer simulation of PEFC systems for automotive applications. The simulation uses thermodynamic data and property utilities, including chemical kinetics and phase and chemical equilibrium routines. Models of the system components consist of $C$ data structures and an associated set of functions. The various flows are represented as $C$ data structures as well. The output of the model of a given component is a function only of the model parameters and input flows (and time for dynamic simulations). Each model maintains mass and energy balance. The thermodynamic and property codes include: the water/steam property code; the Lee-Kesler singlespecies equation of state; the gas-phase chemical equilibrium code (minimization of Gibbs free energy, subject to atom balance constraints); and the multiphase chemical equilibrium code (which simultaneously forces the Gibbs free energies of all phases to zero).

System configurations are defined in terms of component flows and model task loops; the component model functions are called in the order the flows are processed. Cut points are formed to handle recycle streams. Iterative tasks are used to vary the flow parameters at the cut points for convergence. New iterative tasks are added, as needed, to handle parameter sweeps, system constraints, optimizations, and time integrations.

Working with the PNGV Systems Analysis Team, we have developed design and part-load system performance data needed to interface with the hybrid vehicle model developed by Southwest Research Institute (SwRI). Figure 1 shows schematically the various inputs and outputs that were needed at different operating power levels for hydrogen- and gasoline-fueled fuel cell systems. The results of these performance simulations were provided to the PNGV Systems Analysis Team. We continue to work with them to conduct additional simulations, as needed, for the PNGV analyses.

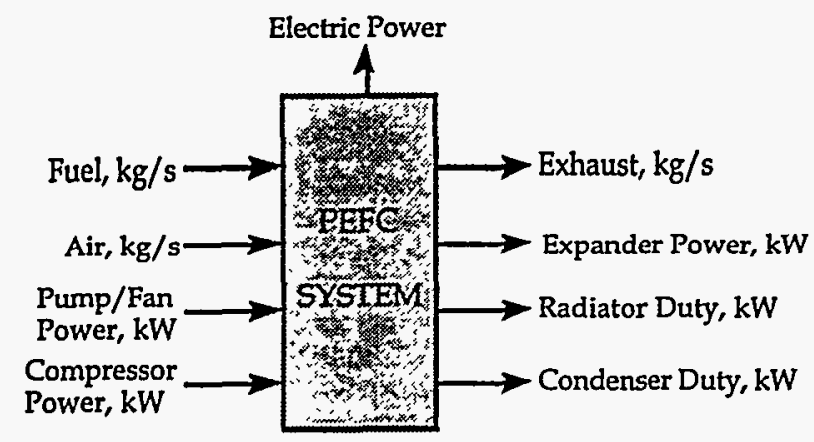

Figure 1. Schematic diagram of the inputs and outputs needed for the SwRI hybrid vehicle model.
Look-up tables derived from our results have been incorporated in the SwRI hybrid vehicle model.

Working with the PNGV Vehicle Engineering Team, we have developed component weight and volume data for use in their vehicle packaging study for a partial-oxidation-reformed PEFC system fueled by gasoline. Three tables of component operational and sizing data were developed for this system, incorporating projected performance values for all of the major components. For a 50-kW (net) system, Table 1 shows the weight and volume results for the major components. Some component volumes were not calculated because automotive hardware configurations of heat exchangers, such as radiators and condensers/ evaporators, are best determined by the PNGV team.

Table 1. Component sizing for the $50-\mathrm{kW}$ partialoxidation-reformed gasoline system

\begin{tabular}{|l|c|c|}
\hline \multicolumn{1}{|c|}{ Component } & $\begin{array}{c}\text { Weight, } \\
\text { kg }\end{array}$ & $\begin{array}{c}\text { Volume, } \\
\text { L }\end{array}$ \\
\hline Fuel cell stack & $80-85$ & 65 \\
\hline Reformer vessel & 100.4 & 110 \\
\hline Desulfurizer & 26 & 23 \\
\hline PROX unit & 8.9 & 9.3 \\
\hline Catalytic burner & 18 & 18 \\
\hline Fuel vaporizer & 4.6 & \\
\hline Radiator (dirty water) & 7 & \\
\hline Condenser & 12 & \\
\hline Radiator, main & 44 & \\
\hline Fuel + fuel tank & 21 & \\
\hline Compressor/expander & 20.2 & 15.5 \\
\hline Pumps, fans, etc. & 9 & \\
\hline Piping and miscellaneous & 28 & \\
\hline
\end{tabular}

One of the issues identified in the packaging study was the large mass of the main radiator and the large air flow rate, $5.05 \mathrm{~kg} / \mathrm{s}$, needed to reject the waste heat at the design operating power level. Further analyses showed that this air flow rate can be decreased to about $1.5 \mathrm{~kg} / \mathrm{s}$ by increasing the temperature of the air leaving the radiator, but with the corresponding penalty of a larger radiator. Also, if the designed-for ambient temperature is increased from $300 \mathrm{~K}(80 \mathrm{EF})$ to $320 \mathrm{~K}$ (116EF), the sizes (and weights) of the main radiator and the turbine exhaust cooler/condenser increase substantially. The size of the main radiator can be reduced by letting the temperature of the fuel cell stack rise (from $353 \mathrm{~K}$ to $363 \mathrm{~K}$, say), but then the 
condenser has to be enlarged to recover sufficient water from the turbine exhaust.

Working with the PNGV Fuel Cell Technical Team, we have developed start-up and dynamic simulations for a hydrogen-fueled Ford ATV Sable and P2000 vehicles. The simulation parameters for the two vehicles are shown in Table 2.

Table 2. Simulation Parameters for AIV Sable and P2000 Vehicles

\begin{tabular}{|l|c|c|}
\hline & AIV Sable & P2000 \\
\hline Test weight, $\mathrm{lb}$ & 3,287 & 2,300 \\
\hline Frontal area, $\mathrm{ft}^{2}$ & 21.3 & 23.5 \\
\hline Drag coefficient & 0.33 & 0.25 \\
\hline Rolling resistance & 0.00776 & 0.0064 \\
\hline Wheel radius, $\mathrm{ft}$ & 1.07 & 1.07 \\
\hline Auxiliary load, $\mathrm{kW}$ & 1.0 & 0.5 \\
\hline
\end{tabular}

Figure 2 shows the instantaneous and average (since the beginning of the cycle) power requirement for the AIV Sable driven on the Federal Urban Driving Schedule (FUDS). Thus, while the maximum power requirement is almost $40 \mathrm{~kW}$, the average power requirement over the entire FUDS is only about $8 \mathrm{~kW}$.

The corresponding instantaneous and cumulative hydrogen consumptions are shown in Fig. 3. The peak hydrogen consumption rate is just under $0.6 \mathrm{~g} / \mathrm{s}$, with a total consumption of about $100 \mathrm{~g}$ over the complete drive cycle.

Similar results were also obtained for the P2000 vehicle. The calculated fuel economy, as equivalent miles per gallon of gasoline, is shown in Fig. 4 for the two vehicles. The fuel economy on the FUDS, highway, and combined driving cycles is shown.

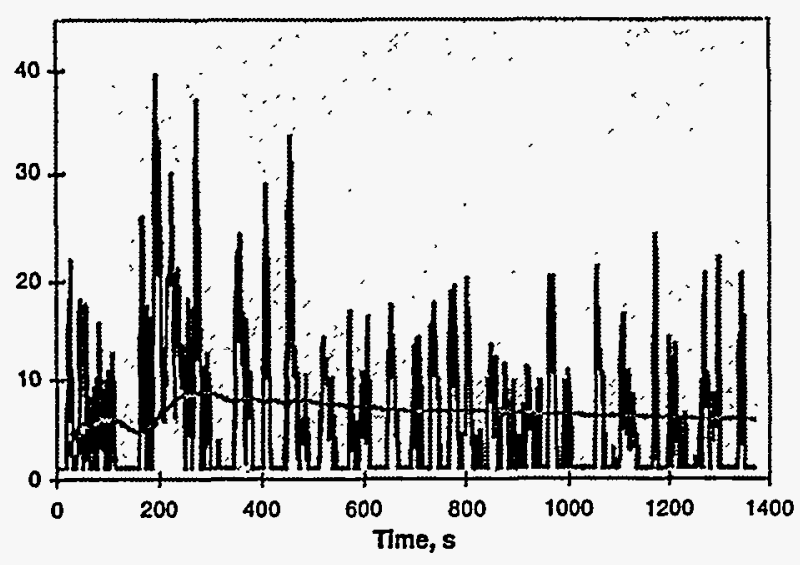

Figure 2. Instantaneous and average power required by the ATV Sable driven on FUDS.

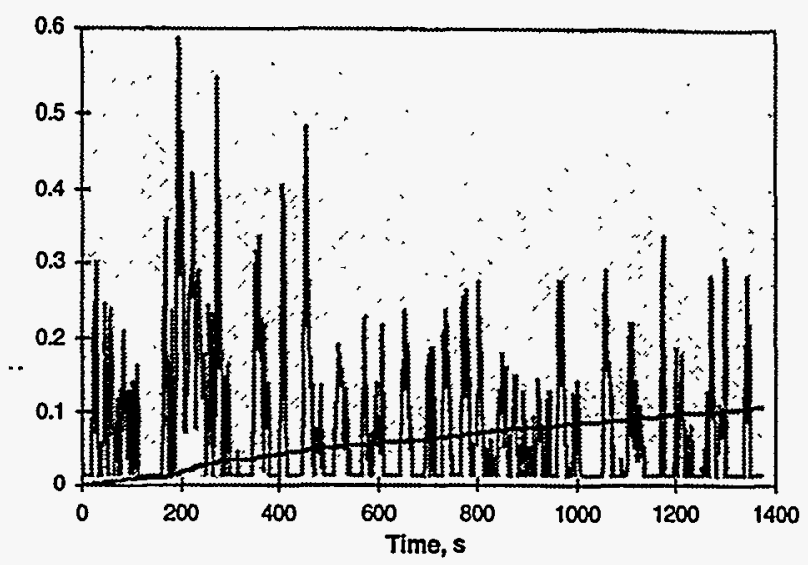

Figure 3. Hydrogen consumption by the AIV Sable driven on the FUDS. Instantaneous consumption in units of $\mathrm{g} / \mathrm{s}$; cumulative in $\mathrm{kg}$.

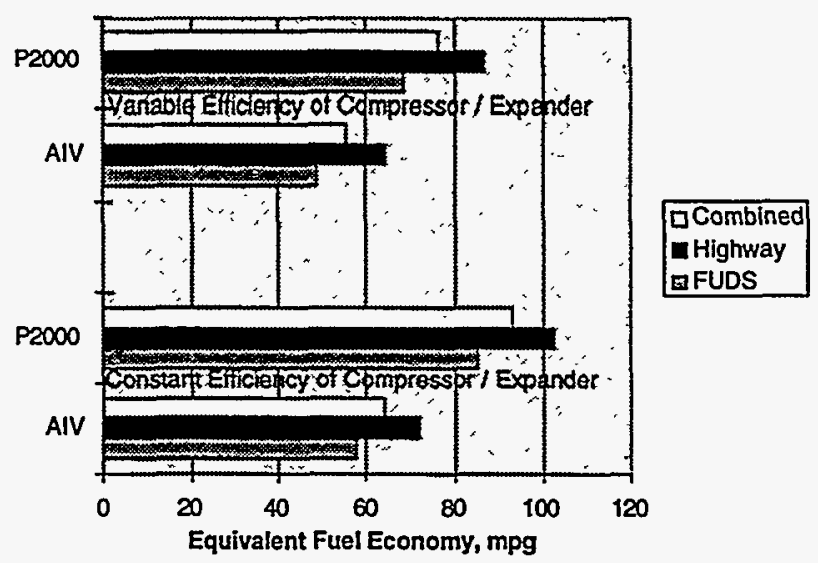

Figure 4. Fuel economy of the AIV Sable and the P2000 vehicles for the FUDS, Highway, and Combined driving cycles.

This figure also shows the effects of two sets of assumptions about the efficiencies of the compressor and expander.

These results indicate that, while the fuel cell AIV Sable shows impressive gains in fuel economy compared to that of the internal combustion engine vehicle, it is not able to meet the goal of $80 \mathrm{mpg}$. On the other hand, the P2000 approaches the $80 \mathrm{mpg}$ fuel economy goal with variable efficiency of the compressor and expander and is expected to exceed that goal if the efficiency of the compressor and expander can be maintained constant over the power range of the fuel cell system.

Future work in fuel cell systems will include (1) dynamic modeling of the gasoline partialoxidation reformer and the PROX unit, and (2) start-up, steady-state, and dynamic modeling of the complete gasoline-fueled system. The component and system models will be validated as operational data become available. 
Fuel Cells for Transportation FY97

\section{B. PEM Stack Modeling at Los Alamos National Laboratory}

Kirk Weisbrod, Jim Lee, Ken Stroh, Mike Inbody and Nick Vanderborgh

MS J576, Fuel Cell Engineering Team,

Los Alamos National Laboratory, Los Alamos, NM 87545

(505) 665-7847, fax: (505) 667-0600

\section{Objectives}

- Develop and apply fundamental fuel cell stack and component models to improve stack designs.

\section{Approach}

- Understand, from a fundamental perspective, attributes of fuel cell stack designs which facilitate electrochemical conversion, mass transport and heat flow.

- Apply model results to guide stack and stack component improvements.

\section{Accomplishments}

- Matched, using the Los Alamos National Laboratory (LANL) 2-D model, down-the-channel variations in current density that were measured using a segmented electrode experiment.

- Designed and began fabrication of a flow visualization cell that will provide required input into the details of 2-phase flow.

\section{Future Direction}

- Include anode kinetics, including specific anode performance loss mechanisms and water transport resistance of catalyst layers in the 2-D model.

- Observe water transport using flow visualization and develop modeling parameters for the computational fluid dynamics (CFD) model.

- Incorporate 2-D model output into the Proton Exchange Membrane (PEM) stack finite difference model.

\section{Introduction/Objectives}

PEM stacks are electrochemical devices whose performance is set both by proper catalyst design and by proper fluid dynamics through the stack hardware. Advances in stack engineering require careful analysis both to evaluate contemporary designs and to suggest improvements. It is the objective of the LANL work to develop verified analytical models that support stack diagnostic technology and shorten the time to commercialization.

\section{Existing Stack Models}

Stack modeling work at LANL has emphasized three specific models: 1) a 2-D mechanistic cell model, 2) a CFD code to represent flow field behavior, and 3) a finite difference model to describe primary heat transfer behavior of operating stacks.

The 2-D model was developed to understand, from a fundamental perspective, the operation of the membrane electrode assembly (MEA) and impact of operating parameters on the performance of that component. Transport of reactant gases and water as well as ionic conductivity of the 
cathode catalyst layer and membrane are modeled based upon first principles, generally with the evaluation of parameters from independent sources. The through-the-electrode component of the model is described elsewhere. ${ }^{1}$ The MEA design parameters that have been explored include catalyst loading, fraction Pt on carbon support, ionomer loading and thickness of the backing layer. Operational parameters include gas composition, liquid and steam partition, discrete water saturation levels, pressure, temperature, electrochemical kinetics and gas momentum terms.

The 2-D model results in predictions of MEA performance down-the-flow channel by accounting for changes in gas composition from consumption of reactants, water production, and transport through the MEA. Accounting for these parameters leads to prediction of the impact of operating parameters including cell temperature, reactant gas pressure and composition, and inlet relative humidity for both the anode and cathode. More details are provided elsewhere. ${ }^{2}$ The code generally shows large variation in the current density along the channel traverse - current PEM devices do not operate with homogeneous conversion rates.

Input parameters for the gas feed streams include temperature, pressure, gas composition, and stoichiometry. The catalyst layer is characterized by oxygen reduction kinetics, ${ }^{3}$ catalyst layer thickness (measured), porosity, liquid saturation (adjustable parameter), ionomer content, and catalyst surface area. The membrane is characterized by its dry thickness, ionic conductivity, ${ }^{4}$ and water diffusivity. ${ }^{4}$ Backing layer thickness and porosity are determined from their initial properties and compressibility. When the presence of liquid water is predicted in a portion of the cathode backing layer, the fraction of the void volume occupied by liquid water (liquid saturation) is input and treated as an adjustable parameter.

\section{First Verification of Non-Homogeneity in Current Density}

Recently, Los Alamos has applied printed circuit board technology to produce a segmented text fixture that permits mapping of current density distributions for an operating PEM single cell. Results from this test fixture built with a parallel-serpentine-flow field were used to validate predictions made by this 2-D model. This is the first set of controlled experimental data available for this purpose.
As mentioned above, input relative humidity is an important modeling input parameter. Therefore the inlet relative humidity of the reactant gases needed to be determined. We evaluated this situation and decided that the test fixture provided an input relative humidity of $70 \%$.

Figure 1 shows the variation in anode and cathode gas relative humidity, cell voltage, and high frequency cell resistance (IR loss through the membrane). Excellent agreement is apparent between model predictions (lines) and the observed current density (symbols). The large "sag" in current density is very apparent. Measured cell voltage is $0.5 \mathrm{~V}$ compared to a value of $0.68 \mathrm{~V}$ from the model; this discrepancy is the result of several possible factors. It is suspected that segmentation of the electrode has decreased electro-catalytic performance and that the cathode backing layer contains a higher water saturation than input to the model.

We also evaluated cell performance as the cathode feed stoichiometry was varied. Figure 2 illustrates the current variation at an air stoichiometry of 1.5, 1.8, and 5.5. The initial rise in performance at $20 \%$ of the channel length is attributed to variations in segment activity. Beyond $50 \%$ of channel length, nearly stable performance is both observed and predicted at a air stoichiometry of 5.5. At an air stoichiometry of 1.8 , cell performance drops compared to the model after $60 \%$ the channel length. When the stoichiometry drops to 1.5, cell performance is significantly below predictions.

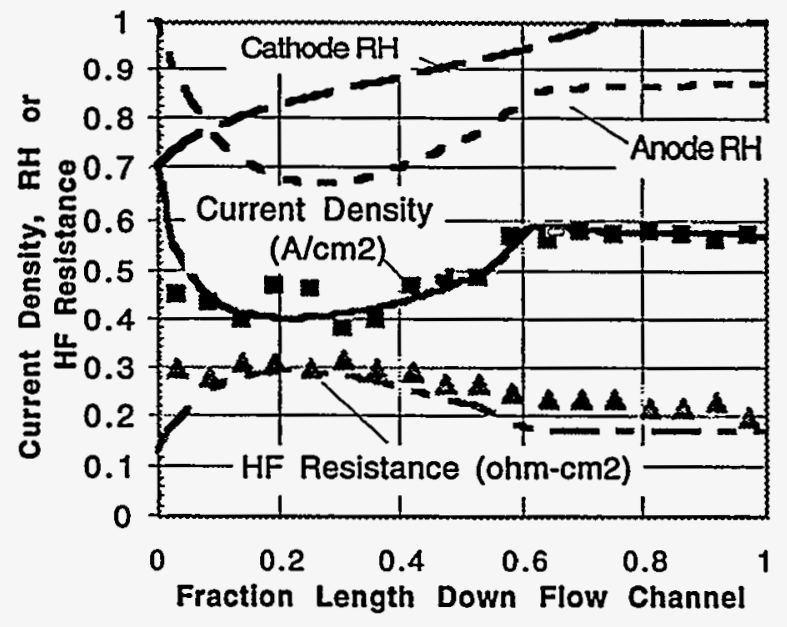

Figure 1. Measured and prediction parameter variation down the flow channel for a $100 \mathrm{~cm}^{2}$ cell at $80^{\circ} \mathrm{C}, 0.5 \mathrm{~V}$. Hydrogen at 0.7 SLPM and $30 \mathrm{psig}$ is humidified at $100^{\circ} \mathrm{C}$. Air at 5 SLPM and 30 psig is humidified at $80^{\circ} \mathrm{C}$. 


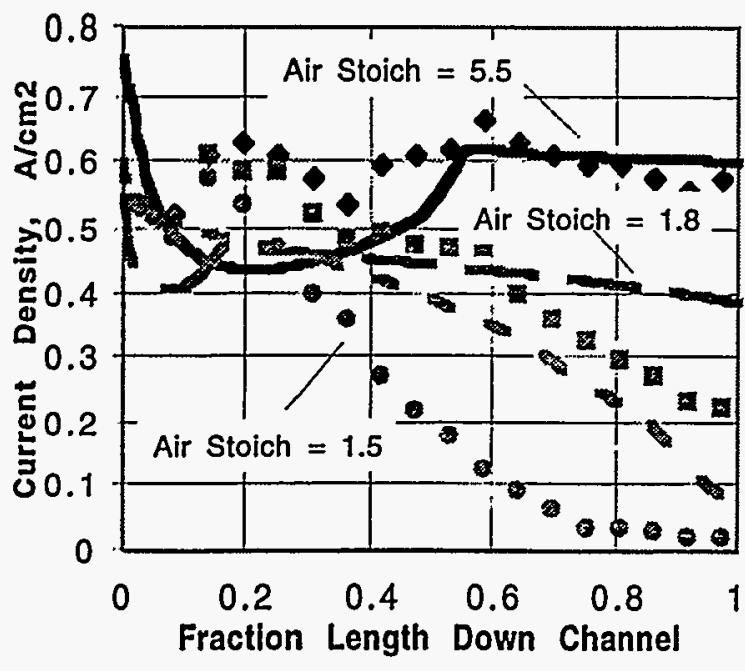

Figure 2. Effect of air stoichiometry upon measured and prediction parameter variation down the flow channel for a $100 \mathrm{~cm}^{2}$ cell at $80^{\circ} \mathrm{C}$. Hydrogen at 0.7 SLPM and $30 \mathrm{psig}$ is humidified at $100^{\circ} \mathrm{C}$. Air at 30 psig is humidified at $80^{\circ} \mathrm{C}$ and fed at a stoichiometry of 1.5, 1.8 and 5.5.

Variation between observed and predicted performance at the end of the flow channel may be attributed to blocking of specific flow features with liquid water. At an air stoichiometry of 1.5 , the calculated pressure drop is $0.2 \mathrm{psi}$. This very small pressure drop provides little force for prompt water removal so inadequate water rejection is suspected. CFD modeling and physical models of the flow fields are being pursued and should provide guidance for flow field development.

We also explored the 2-D model to assess the tradeoff between the pressure volume work required in modern compressor/expander devices with the stack performance gains achieved due to these devices. During model validation, significant deviations between experimental and model results were obtained at low stoichiometries, resulting from imprecise predictions in water flooding parameters. Consequently, the fluid dynamics of air cathodes are not fully understood, and are limited by knowing the actual, site-specific water saturation levels.

\section{Two-Phase Water Visualization}

As illustrated by Figure 2, effective removal of water from flow fields is critical to achieve good stack performance during low stoichiometry (minimal compressor work) operation. To explore the parameters necessary to insure efficient water removal, a physical test fixture with transparent flow fields is being developed (Fig. 3). In this mixture, water is introduced in the anode channels, and then flows through the backing layers and a water permeable membrane. Water flow is set to replicate the production rate of water in an operating fuel cell. (At present this test fixture only replicates uniform current densities.) Optical techniques are the first methods being selected to map the extent of water in the porous layers. Operating conditions and flow field geometries which enhance water removal and minimize blocking may also be explored.

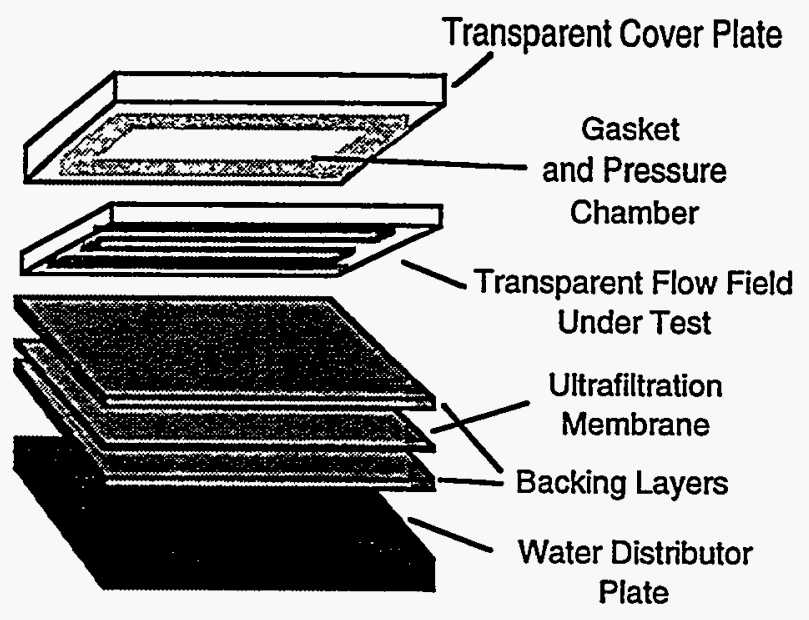

Figure 3. Expanded view of flow visualization hardware for studying water removal parameters.

Other modeling efforts include the use of mechanistic models to isolate the source of stack performance loss with dilute hydrogen feed to the anode and improvements to the finite difference stack model.

\section{REFERENCES}

\section{K. R. Weisbrod, S. A. Grot and}

N. E. Vanderborgh, "Through-the Electrode Model of a Polymer Electrolyte Fuel Cell with Independently Measured Parameters," Electrochemical Society Extended Abstracts, October 8-13, 1995 meeting.

2. K. R. Weisbrod, S. A. Grot and N. E. Vanderborgh, "Two Dimensional Model of a Proton Exchange Membrane Fuel Cell," Fuel Cell Seminar, November 17-20 1996, Kissimmee, FL. 
3. A. Parthasarathy, S. Srinivasan, A.J. Appleby and C.R. Martin J. Electrochem. Soc. 139, 2856 (1992).
4. T. A. Zawodzinki, T. E. Springer, J. Davey,

R. Jestel, C. Lopez, J. Valerio and

S. Gottesfeld, J. Electrochem. Soc. 140, 1981 (1993).

\section{PEM Stack Testing and Evaluation}

Kenneth Stroh, Nicholas Vanderborgh, Michael Inbody, James Lee, Jose Tafoya, James Hedstrom and Kirk Weisbrod

MS J576, Fuel Cell Engineering Team, Los Alamos National Laboratory, P.O. Box 1663, Los Alamos, NM 87545 (505) 667-7933, fax: (505) 665-6173

\section{Objectives}

- Perform dynamic tests on engineering-scale Proton Exchange Membrane (PEM) stacks, including effects of composition and flow rate of anode feeds, to evaluate multifuel reforming system parameters.

- Develop and apply computational fluid dynamics (CFD) models of PEM flow fields and gasdiffusion layers coupled with relevant thermal and electrochemical phenomena.

- Develop advanced modeling and analysis for PEM stack evaluation.

- Investigate problems of interest to Department of Energy Office of Advanced Automotive Technologies (DOE/OAAT) industrial partners.

\section{Approach}

- Maintain and improve flexible and safe engineering-scale stack testing environment.

- Use test results, models, and separate-effects tests (such as flow visualization) to evaluate operating strategies and design options and to project system-level effects.

- Revise and extend models as necessary based on insights gained and new questions raised.

\section{Accomplishments}

- Determined effect on PEM stack performance of anode feeds blended to replicate products from candidate fuel processing systems.

- Developed and applied CFD models of cathode flow fields and gas-diffusion backing layers, furthering understanding of relevant phenomena and effects on performance.

- Identified performance-limiting effects of interaction between cooling features and cell anode water management in large PEM stacks and demonstrated operating strategies to maximize stack performance.

- Supported an OAAT stack developer by performing a documented review of their stack design and development program.

- Successfully froze, demonstrated cold-start, and fully recovered a large PEM stack repeatedly over the range from $-4^{\circ} \mathrm{C}$ to $-18^{\circ} \mathrm{C}$ with no apparent degradation in performance. 
Fuel Cells for Transportation FY97

\section{Future Directions}

- Address issues of PEM stack operation, stack thermal management, and stack diagnostics and control to optimize performance through careful testing (both static and dynamic) and focused modeling.

- Develop technologies for advanced PEM stack diagnostics.

\section{Introduction/Objectives}

PEM stack technology is rapidly expanding worldwide. The DOE's emphasis on gasoline reforming requires new understanding of stack operation with anode feed streams that have far lower hydrogen concentrations than previously anticipated. System optimization requires successful stack operation under these conditions. It is the objective of Los Alamos National Laboratory (LANL) work to facilitate stack improvements, to facilitate good system performance and to promote a reliable testing technology that leads to improved understanding of technical achievements and barriers.

\section{Stack Evaluation Experiments}

PEM stack evaluation at LANL relies on maintaining and improving a flexible and safe test environment. During FY97, testing procedures along with safety protocols were upgraded. New procedures include protection against flammable and toxic gas release, thermal hazards, pressure hazards, and electrical hazards. A thorough, independent safety review was performed and a revised Safe Operating Procedure was put in place to cover the testing operations. In addition, a new, 150-cfm clean (oil-free) air system was installed, and improved instrumentation (IR video, a Fourier Transform Infrared Spectrometer, and a

Quadrapole Mass Spectrometer) was installed. An environmental chamber was acquired and modified for stack testing use. This device controls the external stack temperature and external humidity. Stack testing now can be conducted in a way that includes details of the proposed operational environment. Experimental controls as well as the operator interface were improved. The testing hardware uses UNIX software operating an EPICS controller (Fig. 1.)

The LANL Ballard Mark V stack (SN-212) was used to evaluate the effects of various simulated reformate gas mixtures on stack performance. Mixtures of $\mathrm{H}_{2}, \mathrm{~N}_{2}$, and $\mathrm{CO}_{2}$ simulated reformate from steam-reforming of methanol $\left(75 \% \mathrm{H}_{2^{\prime}}\right.$

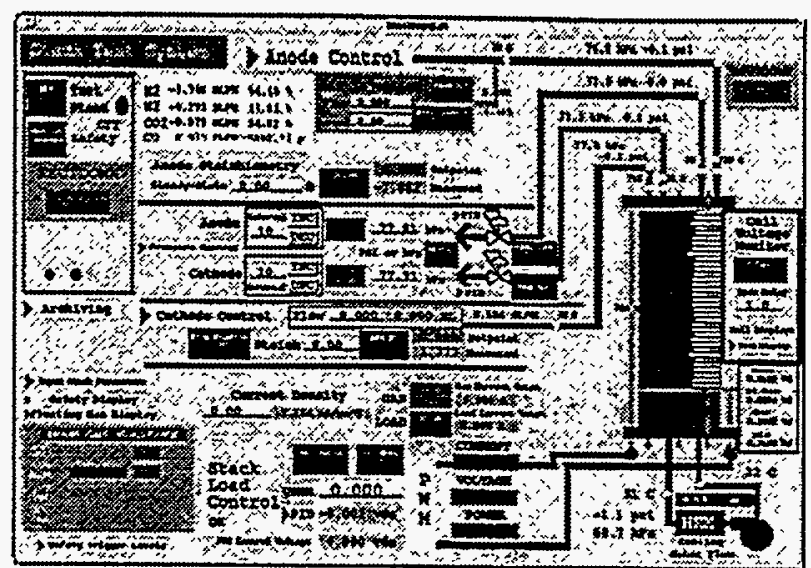

Figure 1. EPICS-controller user interface6 or stack testing. Provides features for safety, data archiving, and control of reactant flow rates (including fixed stoichiometry), pressure, anode gas composition, and load. The histogram on the stack icon displays individual cell voltages in real time.

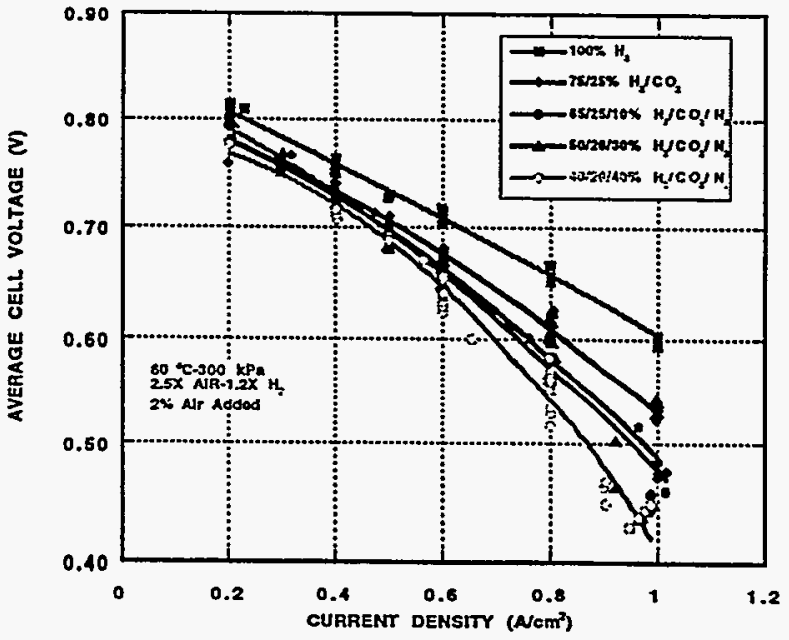

Figure 2. Constant stoichiometry polarization curves for various synthetic reformate mixtures ranging from $75 \% \mathrm{H}_{2}$ and $25 \% \mathrm{CO}_{2}$ to $40 \% \mathrm{H}_{2}$, $20 \% \mathrm{CO}_{2}$ and $40 \% \mathrm{~N}_{2}$. The top curve shows performance on pure hydrogen. 
THERMAL EFFECTS TEST, BALLARD SN212

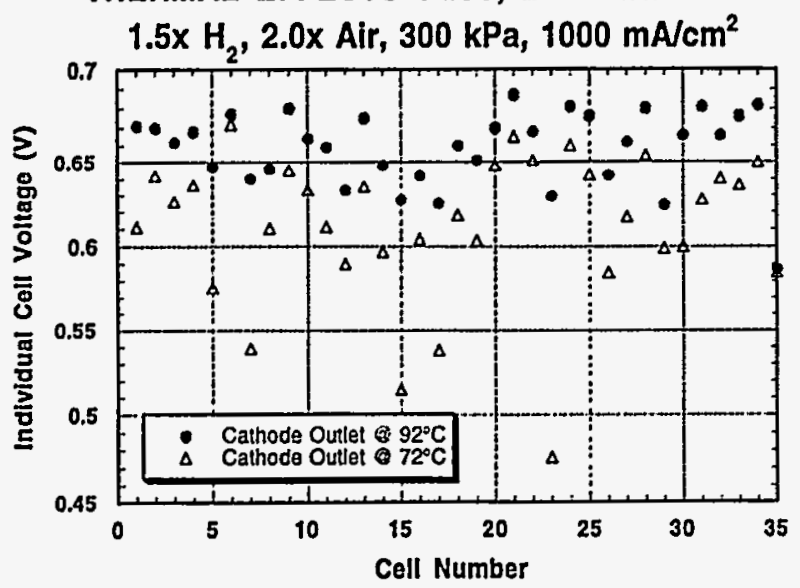

Figure 3. Effect of two stack operating temperatures on individual cell voltages in a Ballard Mark $V$ stack. Low voltages at $72^{\circ} \mathrm{C}$ are highly correlated with cells having their anode against a cooling plate.

$25 \% \mathrm{CO}_{2}$ ), methanol auto-thermal reforming $\left(65 \% \mathrm{H}_{2}, 25 \% \mathrm{CO}_{2}, 10 \% \mathrm{~N}_{2}\right)$, partial oxidation of ethanol $\left(50 \% \mathrm{H}_{2}, 20 \% \mathrm{CO}_{2}\right.$, and $\left.30 \% \mathrm{~N}_{2}\right)$, and partial oxidation of gasoline or diesel $\left(40 \% \mathrm{H}_{2}\right.$, $20 \% \mathrm{CO}_{2}, 40 \% \mathrm{~N}_{2}$ ).

The Ballard test article is built with high loadings of anode catalyst. Even with these anode loadings, stack performance was severely impacted by both hydrogen dilution and by the presence of $\mathrm{CO}_{2}$ For example, using synthetic partial oxidation reformer (POX) gasoline reformate, the performance loss at a current densities approaching $1 \mathrm{~A} / \mathrm{cm}^{2}$ was nearly $200 \mathrm{mV}$, compared with stack performance on pure hydrogen. The performance loss with $20 \% \mathrm{CO}_{2}$ and $40 \% \mathrm{~N}_{2}$ was approximately $90 \mathrm{mV}$ greater than was the performance loss caused by dilution with $60 \% \mathrm{~N}_{2}$, even with $2 \%$ air bleed into the anode feed. At $0.5 \mathrm{~A} / \mathrm{cm}^{2}$, the performance loss on synthetic POX gasoline reformate was approximately $70 \mathrm{mV}$. For this particular stack and at the operating conditions of these tests $\left(80^{\circ} \mathrm{C}\right.$ operating temperature, anode and cathode at $300 \mathrm{kPa}$, cathode stoichiometry of 2.5 and anode stoichiometry of 1.2), operation on synthetic POX gasoline reformate lowered overall stack peak power by more than $30 \%$, and stack efficiency at peak power by more than 5 percentage points. Fortunately, there is a much smaller efficiency penalty at part load. These tests suggest, however, that the stack with these poor performance characteristics would have to be considerably larger for a POX gasoline system than for a direct hydrogen system.
The exact causes of this performance are not totally understood. Nitrogen losses are most likely caused by flow blockage in the porous layers and by hydrogen dilution in the electrolyte film. Carbon dioxide, because of higher solubility in the electrolyte, is probably more effective in lowering hydrogen solubility and should exhibit similar flooding tendencies. However, carbon dioxide may also be chemically reduced to form a $\mathrm{Pt}-\mathrm{C}-\mathrm{OH}$ intermediate, and that could also lower reactivity. Tests are in progress to sort through these possible causes. Through the introduction of contaminant tolerant catalyst surfaces and manufacture of thin layer structures less prone to restrict reactant flow, modern electrode design will do much to change this situation. It can be concluded that the older Ballard stack article demonstrates appreciable voltage loss, but improved designs will do much to eliminate these effects. LANL will investigate more modern electrode designs during FY98.

\section{Temperature Gradients during Stack Performance}

An ongoing FY97 activity involves providing technical support to US companies developing fuel cell technology. During one such interaction, a systematic pattern of low-voltage cells was observed during stack testing. Subsequent testing at LANL revealed a similar pattern could be obtained under "in family" operating conditions of the Ballard Mark V stack, and furthermore, that this pattern of poor-performing cells had a high correlation with those cells with anodes adjacent to a cooling plate. Operating the stack at higher temperatures essentially eliminated this effect, supporting the hypothesis that anode flooding (path disruption or blockage) due to increased condensation of liquid water in cooler cells is the cause of the observed decreased performance. (The anode is thought to be more susceptible to mass transfer limitations than the cathode because of much lower flow momemtum).

These tests support the notion that thermal management is a critical element in PEM stacks design. At LANL, we are addressing this by ongoing model development, including threedimensional thermal modeling and by additional focused stack testing. Work on CFD models with coupled electrochemical and thermal phenomena has been folded into this industrial-support task. A flow and water-management visualization experiment is underway to confirm model results and reveal relevant effects. 


\section{Low Temperature PEM System Excur- sions:}

Automotive fuel cell applications require the system to survive a storage environment that extends well below the freezing point of water. There is continued interest in the implications of a specification to meet temperature requirements in a system that produces liquid water as a product.

LANL responded to a request to address concerns from another of OAAT's industrial partners related to PEM stack freezing and subsequent cold start. We successfully froze and recovered the Ballard Mark V stack repeatedly and demonstrated self-startup using cold reactant gases with internal losses, providing the only stack heating until all measured temperatures were above freezing.

We began by "de-watering" the stack using dry nitrogen to purge the anode and cooling/humidifier circuits and using air to purge the cathode circuit. We then reduced the stack internal temperature to $-4^{\circ} \mathrm{C}$ and held it there overnight. On the first test, we let the stack thaw overnight in the closed chamber and warmed it with a heater in the cooling loop prior to operation. In subsequent tests, we supplied reactant gases (pure hydrogen and air) to the frozen stack at essentially atmo- spheric pressure (no back-pressure regulation) and at flows consistent with low current density operation and applied small electrical loads. Stack inefficiencies at these very cold operating conditions appear as heat throughout the stack active volume. This self-heating was used to bring all measured temperatures above freezing. At this point, the cooling loop was filled and the stack was warmed to normal operating temperature, where polarization curves were generated. No degradation in performance could be detected through three freeze-thaw cycles (the third to $-18^{\circ} \mathrm{C}$ ) and two cold-start cycles (from both $-4^{\circ} \mathrm{C}$ and $-18^{\circ} \mathrm{C}$ ). These tests showed there are no inherent limitations in exposing this PEM stack to ambient conditions down to $-18^{\circ} \mathrm{C}$. We did find, however, that efficient stack de-watering and cold-start strategies, which are likely very design dependent, will require considerable work.

\section{PUBLICATIONS}

K. Stroh, J. Tafoya, M. Inbody and N. Vanderborgh, "Freezing, Cold Start and Recovery of a Proton Exchange Membrane Fuel Cell Stack," (in preparation, Journal of Power Sources). 


\title{
V. DIRECT METHANOL FEM FUEL CELLS
}

\author{
Direct Methanol Fuel Cells
}

Xiaoming Ren, Simon Cleghorn, Sharon Thomas, Piotr Zelenay and Shimshon Gottesfeld

MS D429, Los Alamos National Laboratory

Los Alamos, NM 87545

(505)667-0853, fax: 505-665-4292

\section{Objectives}

- Examine the potential of Direct Methanol Fuel Cells (DMFCs) for replacing the complex systems in transportation applications that are based on reforming liquid fuels on board.

\section{Approach}

- Prove viability of DMFCs by demonstrating operating temperatures of $100^{\circ} \mathrm{C}$ or above with $>80 \%$ fuel efficiency and long term stability.

\section{Accomplishments}

- Demonstrated 1000 hours of stable DMFC operation at $\mathrm{T}>100^{\circ} \mathrm{C}$

- Demonstrated DMFC (methanol/air) generating $100 \mathrm{~mA} / \mathrm{cm}^{2}$ at $0.5 \mathrm{~V}$ with less than $1 \mathrm{mg}$ precious metal anode catalyst $/ \mathrm{cm}^{2}$

- Demonstrated DMFC (methanol/air) operating at or above $100^{\circ} \mathrm{C}$ with fuel utilization of $80 \%$ and maximum power density of $0.15 \mathrm{~W} / \mathrm{cm}^{2}$.

\section{Future Directions}

- Lower anode catalyst loadings in DMFCs developed for transportation applications by a factor of two.

- Lower the cross-over rate through an ordinary $\left(\mathrm{Nafion}^{\mathrm{R}} \mathrm{117}\right)$ ionomeric membrane to near zero.

In this chapter of our work for the Fuel Cell Core Research Program of the Department of Energy's Office of Advanced Automotive Technologies (DOE/OAAT), we have examined the potential of Direct Methanol Fuel Cells (DMFCs) for replacing in transportation applications the complex systems based on reforming liquid fuels on board. DMFCs offer the attractive simplicity of direct conversion of liquid fuel to electricity in a low temperature $\left(60-120^{\circ} \mathrm{C}\right)$ fuel cell associated with low emission levels and built of benign materials. In order for DMFCs to compete favorably with transportation systems based on stack fueling by hydrogen rich feed streams (reformates), the DMFC power density has to approach that of reformate/air cells (probably within factor 2-3), and the DMFCs must demonstrate high fuel efficiencies $(>80 \%)$, long-term stability, and catalyst loadings significantly lower than required to date.

Our conclusion has been that a DMFC has to operate at temperatures of $100^{\circ} \mathrm{C}$ or above to achieve such targets. This is because cell power density for direct feed of methanol as well as the fuel efficiency can be improved substantially in a polymer electrolyte cell by raising the temperature to the upper limit determined by membrane stability constraints. 
Our milestones in this effort for FY 1997 have been:

- Demonstrate 1000 hours of stable DMFC operation at $\mathrm{T}>100^{\circ} \mathrm{C}$.

- Demonstrate DMFC (methanol/air) generating $100 \mathrm{~mA} / \mathrm{cm}^{2}$ at $0.5 \mathrm{~V}$ with less than $1 \mathrm{mg}$ precious metal anode catalyst $/ \mathrm{cm}^{2}$.

- Demonstrate DMFC (methanol/air) operating at or above $100^{\circ} \mathrm{C}$ with fuel utilization of $80 \%$ and maximum power density of $0.15 \mathrm{~W} / \mathrm{cm}^{2}$.

All milestones were met.

Figure 1 above shows recent advancements made at Los Alamos National Laboratory (LANL) in demonstrated cell life and cell performance for DMFCs operated on $1 \mathrm{M} \mathrm{MeOH}$ anode feed. The important aspects of the achievements in FY97 demonstrated in Figure 1: (a) the enhanced DMFC performance with air, rather than oxygen cathode, demonstrated at the elevated temperature of $100^{\circ} \mathrm{C}$, and (b) the ability to keep the enhanced performance stable during several hundred hours of continuous operation at high cell temperatures.

Figure 2 further elucidates the improvement in cell performance of methanol/air cells achieved at LANL during the last year with air cathodes at 30 psig. This improvement has been the result of improved anode catalyst and catalyst layer preparation as well as improvements in cathode backing layer properties. Figure 2 shows that the current density achievable at $0.5 \mathrm{~V}$ with our DMFCs has practically doubled as a result of these improvements in anode and cathode sides. This amounts to

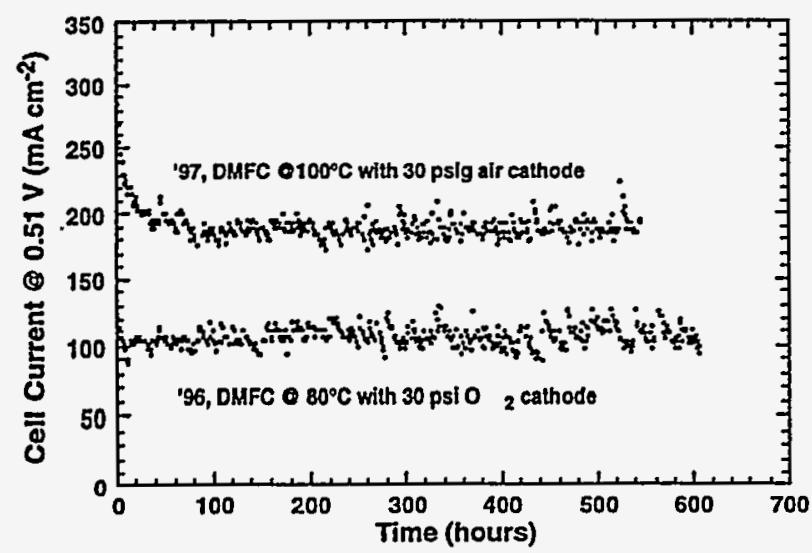

Figure 1. Life tests of a $\left(5 \mathrm{~cm}^{2}\right)$ DMFC at Los Alamos National Laboratory - FY97 vs. FY96 achievements.

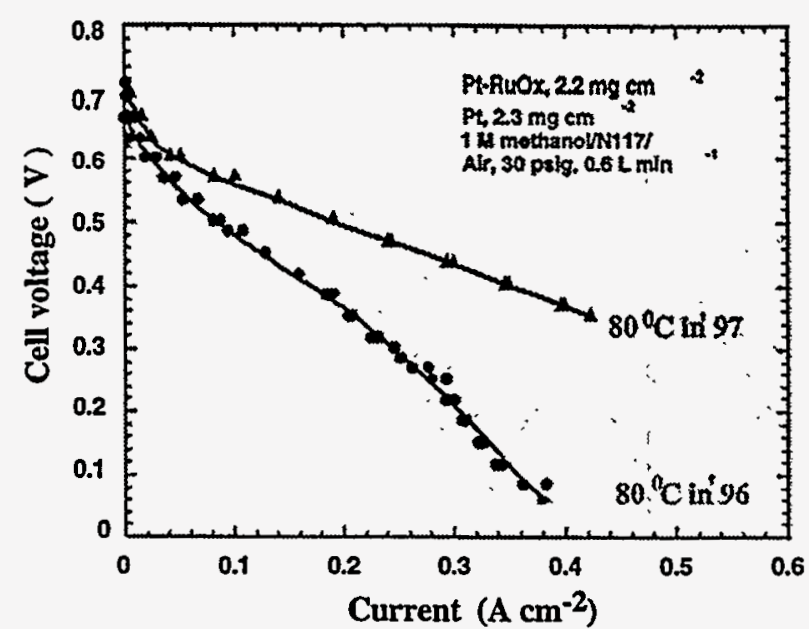

Figure 2. Cell performance of methanol/air cells with air cathodes at 30 psig in FY96 and FY97.

an increase by factor two in power density at the design point usually considered for DMFCs $(0.5 \mathrm{~V})$.

Figure 3 below demonstrates the ability to achieve, at higher cell temperatures, very reasonable cell performance in methanol/air cells with anode catalyst loadings lower than $1 \mathrm{mg} / \mathrm{cm}^{2}$. While further efforts are definitely required to further lower anode catalyst loadings in DMFCs developed for transportation applications, the present day gap between anode catalyst loadings required to achieve best demonstrated performances from PEFCs with liquid fuel reformates and from DMFCs is only about a factor of two.

Finally, the other well-known technical barrier for implementing DMFCs has been the significant rate of methanol cross-over through ionomeric membranes. During this year, we have demonstrated that, under appropriate anode operation

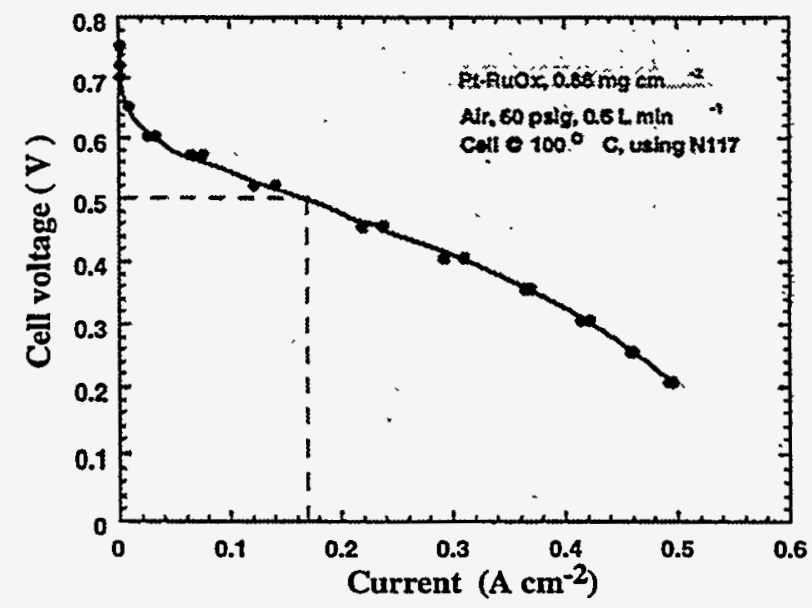

Figure 3. Methanol/air cell performance at $100^{\circ} \mathrm{C}$ with anode catalyst loading $<1 \mathrm{mgPtRu} / \mathrm{cm}^{2}$. 
conditions, the cross-over rate through an ordinary (Nafion $^{\mathrm{R}} 117$ ) ionomeric membrane could be lowered to practically zero at cell temperatures close to $100^{\circ} \mathrm{C}$. This was achieved at a penalty in cell power density of about factor 2 , but further optimization of DMFC operation conditions under conditions allowing such ultra-low cross-over rates (achieved with ordinary membranes), seems possible.

\title{
B. Application of Combinatorial Synthetic Methods to the Development of Electrocatalysts for Direct Alcohol Oxidation
}

\author{
Daniel L. DuBois \\ National Renewable Energy Laboratory, \\ 1617 Cole Boulevard, Golden, CO 80303-3393
}

\section{Objectives}

- Develop new catalysts for the direct electrochemical oxidation of alcohols.

- Develop new screening methods for rapidly identifying potential electrocatalysts of interest.

\section{Approach}

- Prepare metal ions and ligands suitable for use as building blocks.

- Construct libraries of metal complexes and metal particles from building blocks.

- Transfer libraries to electrode surfaces.

- Screen arrays of electrodes for catalytic activity for alcohol oxidation.

\section{Accomplishments}

- A variety of weakly solvated metal ions and positively charged ligands suitable for constructing libraries have been prepared.

- Studies have been carried out to determine optimal conditions for transferring positively charged metal ions and complexes to electrode surfaces.

\section{Future Directions}

- Construct and screen arrays of electrodes for alcohol oxidation.

In the past five years, combinatorial chemistry has been applied primarily to drug design and has resulted in the rapid development of a number of new drug candidates. ${ }^{1-2}$ Combinatorial synthesis has also been successfully applied to the development of peptide, oligonucleotide, organic, heterogeneous, and transition metal catalysts. ${ }^{3.7} \mathrm{We}$ would like to extend this approach to the development of catalysts for alcohol oxidation.
In order to achieve this goal, we have synthesized 10-15 transition metal complexes with weakly coordinating acetonitrile ligands and approximately 30 ligands with positive charges. These compounds constitute the building blocks from which the libraries will be prepared. Weakly solvated metal complexes are desirable as building blocks because the solvent ligands will be readily displaced by the more strongly binding ligands 
added during the synthesis of library members. In addition, those sites at which the solvent remains as the ligand will serve as active sites for catalytic reactions. Positively charged ligands with nitrogen, oxygen, phosphorus, and sulfur donor atoms were also prepared and should allow considerable control of the donor set of the metal complexes. In addition, the positive charge on these ligands should insure binding of the resulting complexes to Nafion membranes used to coat the graphite electrodes. This synthetic work has been carried out in the last six months with funding from the FIRST program at the National Renewable Energy Laboratory.

The method chosen for isolation of potential catalysts involves incorporating cationic complexes into Nafion membranes coated on graphite electrodes. This procedure permits simultaneous removal of the library members from solution and modification of the electrodes for screening. If this step is not reliable, meaningful results from the screening process will not be possible. We have used ${ }^{31} \mathrm{P}$ nuclear magnetic resonance spectroscopy to monitor the incorporation of positively charged complexes into Nafion membranes. This method was chosen because it is quantitative, but does not depend on such parameters as the rate of electron transfer to the metal complexes or the rate of diffusion of the metal complexes as would be true for electrochemical techniques. This technique is also capable of providing detailed structural information about the cations incorporated. A number of cationic forms of Nafion were investigated including acid, sodium, potassium, lithium, and tetraethylammonium forms. Various solvents were also studied including water, acetone, acetonitrile, dichloromethane, and dimethylformamide. The most reliable incorporation of the transition . metal cations was observed for the lithium form of Nafion using dimethylformamide as the solvent. We have also briefly explored the effect of the size and charge of the metal complex being incorpo- rated into Nafion. Increased charge was shown to slow the rate of incorporation and cations with diameters larger than approximately 20 angstroms were found to completely suppress incorporation.

The thickness of the Nafion membrane was optimized to obtain the best cyclic voltammograms of incorporated metal complexes. The best responses were generally obtained for membrane thicknesses estimated to be between 10 and 100 monolayers. This is the range that will be used for preparing the libraries of electrodes.

The next step involves the actual synthesis of a library of electrodes modified with a variety of metal complexes and metal particles. This is one of the major activities planned for the next year. Once the electrode libraries have been prepared, they will be screened for their ability to catalytically oxidize alcohols.

\section{REFERENCES}

1. Czarnik, A. W. Acc. Chem. Res., 29, 112-113 (1996).

2. Baum, R. Chem. Eng. News, 74(7), 28-73 (1996).

3. Hsieh-Wilson, L. C., X.-D. Xiang and

P. G. Schultz, Acc. Chem. Res., 29, 164-170 (1996).

4. Menger, F. M., A. V. Eliseev and V. A. Migulin, J. Org. Chem., 60, 6666-6667 (1995).

5. Mallouk, T. E., E. Reddington, C. Pu, K. L.Ley and E. S. Smotkin, Fuel Cell, 1996 Fuel Cell Seminar, p. 686, Nov. 17-20, Orlando Florida (1996).

6. Baker, B. E., N. J. Kline, P. J. Treado and M. J. Natan, J. Am. Chem. Soc., 118, 8721 (1996).

7. Cole, B. M.; K. D. Shimizu, C. A. Krueger, J. P. A. Harrity, M. L. Snapper and A. H. Hoveyda, Angew. Chem. Int. Ed. Engl., 35, 1668 (1996). 


\section{SOLID OXIDE FUEL CELLS}

\section{Low Temperature Solid Oxide Fuel Cells}

Rajiv Doshi, Von L. Richards, Jennifer Wagar and Michael Krumpelt

Argonne National Laboratory, Argonne, IL 60439-4837

(630) 252-4787, fax: (630) 252-4176

\section{Objectives}

- Decrease cathode polarization from $10 \mathrm{~W}-\mathrm{cm}^{2}$ to below $2 \mathrm{~W}-\mathrm{cm}^{2}$.

- Decrease resistance through the electrolyte.

- Achieve a cell performance of at least $75 \mathrm{~mW} / \mathrm{cm}^{2}$ at $500^{\circ} \mathrm{C}$.

\section{Approach}

- Develop higher performance cathodes by increasing the ionic and electronic conductivities of the materials and/or by adding an electrolyte phase to the cathode to increase ionic conductivity.

- Fabricate electrolyte layers with thickness less than $400 \mu \mathrm{m}$.

- Apply improved cathode materials/microstructures to the thin electrolytes to obtain high cell performance.

\section{Accomplishments}

- Developed new cathode compositions and microstructures with improved cathode performance, giving cathode polarization resistance of $<1 \mathrm{~W}-\mathrm{cm}^{2}$.

- Fabricated flat tape-cast electrolytes with $\sim 250-\mu \mathrm{m}$ thickness and also bilayers with a $30-\mu \mathrm{m}$-thick dense electrolyte film supported on a $250-\mu \mathrm{m}$-thick anode.

- Demonstrated a cell performance of $140 \mathrm{~mW} / \mathrm{cm}^{2}$ at $500^{\circ} \mathrm{C}$ in $50 \% \mathrm{H}_{2}$ and air at $1 \mathrm{~atm}$ pressure.

\section{Future Directions}

- Increase fuel cell performance by at least a factor two.

- Test high-performance cells with gasoline reformate.

Unlike phosphoric acid and polymer electrolyte fuel cells, solid oxide fuel cells (SOFCs) can be operated on fuel gases containing carbon monoxide so that liquid fuels can be used conveniently in transportation fuel cell systems based on SOFCs. The major perceived drawback of SOFCs for transportation applications is the relatively high operating temperature, which would require a significant start-up time. By reducing the operating temperature to the range of $500-700^{\circ} \mathrm{C}$, however, the start-up time of the fuel cell stack could be comparable to that of the fuel processor, and the combination of the two would represent a simple and inexpensive system.

Low temperature solid oxide fuel cells (LTSOFCs) operating at $500-700^{\circ} \mathrm{C}$ with direct 